\title{
Digital Platform Informed Certification of Components Derived from Advanced Manufacturing Technologies
}

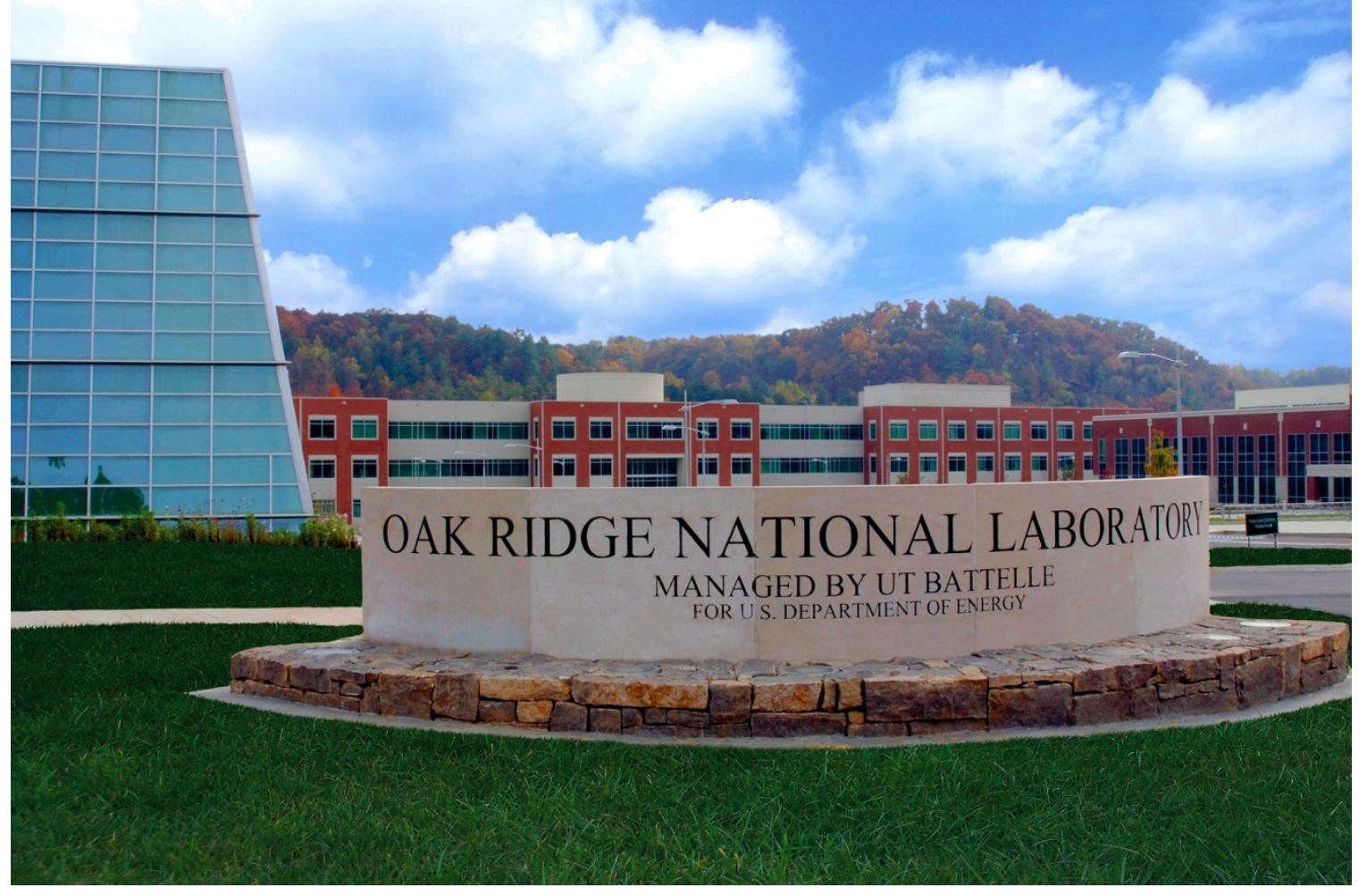

\begin{abstract}
A. Huning et al.
\end{abstract}
September 2021

M2TC-21OR0405013

OAK RIDGE 


\section{DOCUMENT AVAILABILITY}

Reports produced after January 1, 1996, are generally available free via US Department of Energy (DOE) SciTech Connect.

Website www.osti.gov

Reports produced before January 1, 1996, may be purchased by members of the public from the following source:

National Technical Information Service

5285 Port Royal Road

Springfield, VA 22161

Telephone 703-605-6000 (1-800-553-6847)

TDD 703-487-4639

Fax 703-605-6900

E-mail info@ntis.gov

Website http://classic.ntis.gov/

Reports are available to DOE employees, DOE contractors, Energy Technology Data Exchange representatives, and International Nuclear Information System representatives from the following source:

Office of Scientific and Technical Information

PO Box 62

Oak Ridge, TN 37831

Telephone 865-576-8401

Fax 865-576-5728

E-mail reports@osti.gov

Website http://www.osti.gov/contact.html 
Transformational Challenge Reactor

\title{
DIGITAL PLATFORM INFORMED CERTIFICATION OF COMPONENTS DERIVED FROM ADVANCED MANUFACTURING TECHNOLOGIES
}

\author{
Alexander Huning, Randall Fair, Alyson Coates, Vincent Paquit, \\ Luke Scime, Michael Russell, Kenneth Kane, Samuel Bell, \\ Bruce Lin, and Benjamin Betzler
}

September 2021

M2TC-21OR0405013

Prepared by

OAK RIDGE NATIONAL LABORATORY

Oak Ridge, TN 37831-6283

managed by

UT-BATTELLE LLC

for the

US DEPARTMENT OF ENERGY

under contract DE-AC05-00OR22725 



\section{CONTENTS}

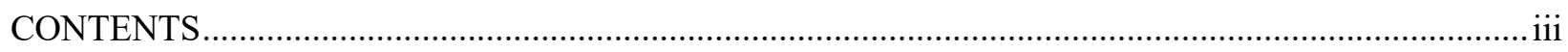

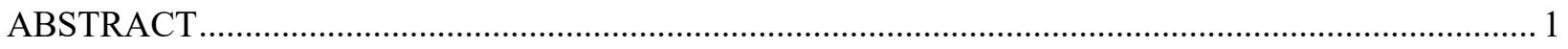

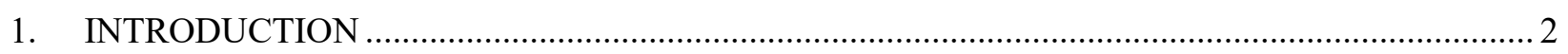

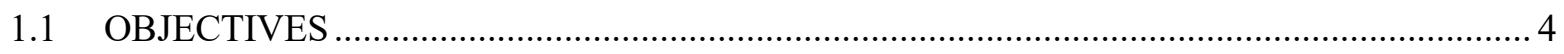

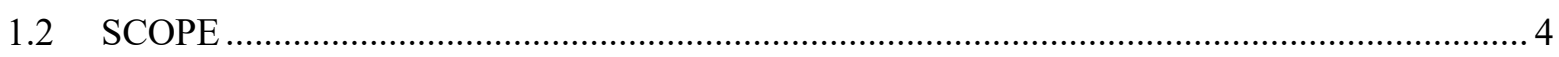

1.3 AMT vs TRADITIONAL MATERIALS ........................................................................ 5

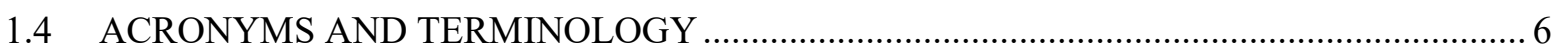

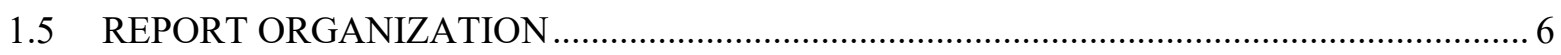

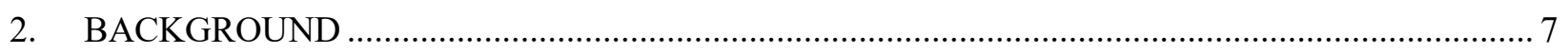

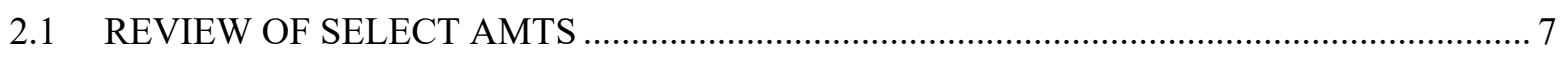

2.2 NON-NUCLEAR AMT APPLICATIONS AND QUALIFICATION ASPECTS .................. 12

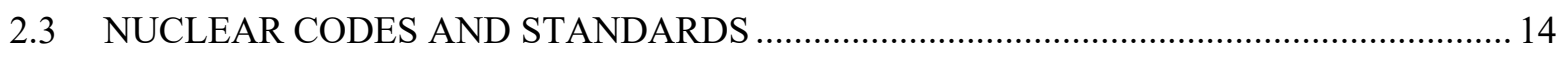

2.4 NUCLEAR REGULATORY COMMISSION INITIATIVES ............................................... 15

2.5 OTHER NUCLEAR INDUSTRY AMT INITIATIVES ...................................................... 18

2.6 DIGITAL PLATFORM AND ARTIFICIAL INTELLIGENCE .............................................. 20

3. APPROACH TOWARDS DIGITAL PLATFORM INFORMED CERTIFICATION .......................2 23

4. TCR APPLICATION EXAMPLE OF DIGITAL PLATFORM INFORMED

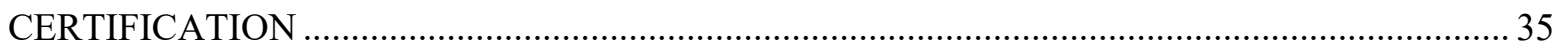

4.1 TCR INFRASTRUCTURE AND PROGRAM GOALS ..................................................... 35

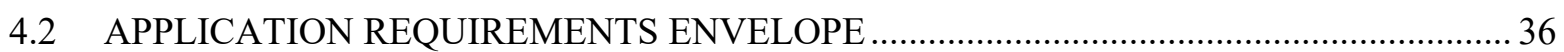

4.3 PROCESS AND DIGITAL PLATFORM QUALIFICATIONS ............................................... 37

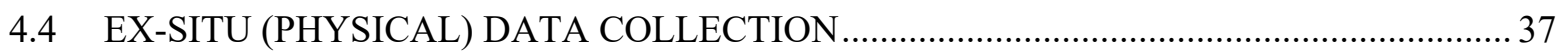

4.5 PRODUCTION AND VERIFICATION TESTING .......................................................... 38

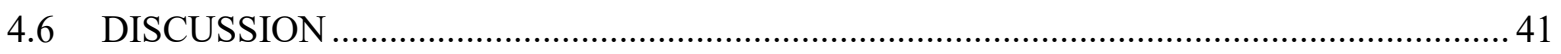

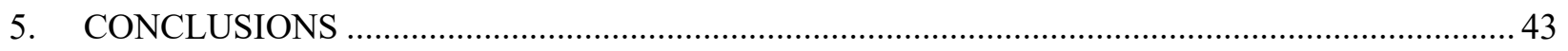

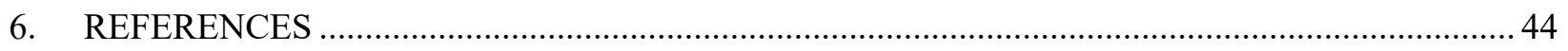

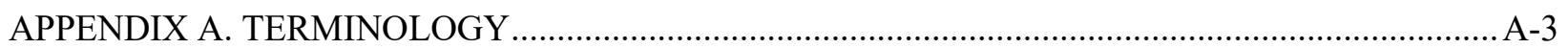




\begin{abstract}
The Transformational Challenge Reactor is being designed at Oak Ridge National Laboratory to demonstrate the feasibility of constructing a reactor core using advanced manufacturing technology. This technology includes additive manufacturing combined with machine learning, materials science, and data science technologies in an effort to facilitate the expansion of additive manufacturing into advanced nuclear energy systems and other applications requiring a high level of quality assurance. The Transformational Challenge Reactor is employing additive manufacturing and artificial intelligence to deliver a new approach. Beginning in FY21, the focus of the program has shifted away from demonstrating a reactor, and instead, towards delivering on four key thrust areas: (1) artificial intelligence-informed design, (2) advanced materials, (3) integrated sensing and control, and (4) the digital platform. Of these four thrust areas, the most pertinent to this report is the digital platform. The digital platform has the potential to be a key enabler for a paradigm shift in how components, those derived from advanced manufacturing technologies, are certified for use in nuclear applications. This is achieved primarily using machine learning to discover correlations from the abundance of data produced through additive manufacturing and those physical properties critical to the performance of the component.
\end{abstract}

A proposed approach towards the certification of advanced manufacturing technology-derived components using the digital platform is presented. This approach has similarities to and builds on those industry initiatives already in progress to qualify advanced manufacturing technology-derived components. However, aspects of where data and the digital platform can integrate with, are especially highlighted. This proposed approach is:

a. generic (can be applicable to any advanced manufacturing technology, any supported material, and any application which may have a strong safety significance),

b. flexible (can be scaled to large programs with a variety of advanced manufacturing technologyderived component applications, or small programs that have only a few, but clearly defined desired applications),

c. complementary to existing industry approaches under development (those being developed by the U.S. Nuclear Regulatory Commission and other industry trade groups), and,

d. performance-based (allows for operational feedback and building confidence in the digital platform).

To envelop these attributes, a simple demonstration has been designed to employ the digital platform for component scale performance predictions. Results from this demonstration are expected around the time of publishing this report and therefore, will be presented in a follow-up report.

The digital platform has the potential to transform how concepts of equivalency and expected component performance are measured. Currently, there is no discussion or pathway for using the data and artificial intelligence embedded within the digital platform to demonstrate equivalency and expected component performance. This report explores how the digital platform could integrate with the regulatory framework being proposed by the U.S. Nuclear Regulatory Commission for advanced manufacturing component development. 


\section{INTRODUCTION}

The Transformational Challenge Reactor (TCR) is being designed at Oak Ridge National Laboratory (ORNL) to demonstrate the feasibility of constructing a reactor core using advanced manufacturing technology (AMT). This technology includes additive manufacturing (AM) combined with machine learning, materials science, and data science technologies in an effort to facilitate the expansion of AM into advanced nuclear energy systems and other applications requiring a high level of quality assurance. The TCR is employing AM and artificial intelligence (AI) ${ }^{1}$ to deliver a new approach to manufacturing for nuclear components.

In the fall of 2020, the TCR reactor design was refocused in favor of more concentrated efforts in four key thrust areas: (1) AI-informed design, (2) advanced materials, (3) integrated sensing and control, and (4) the digital platform. Figure 1 illustrates the four key technical thrust areas for the TCR program. Of particular interest is the digital platform and it is discussed throughout this report.

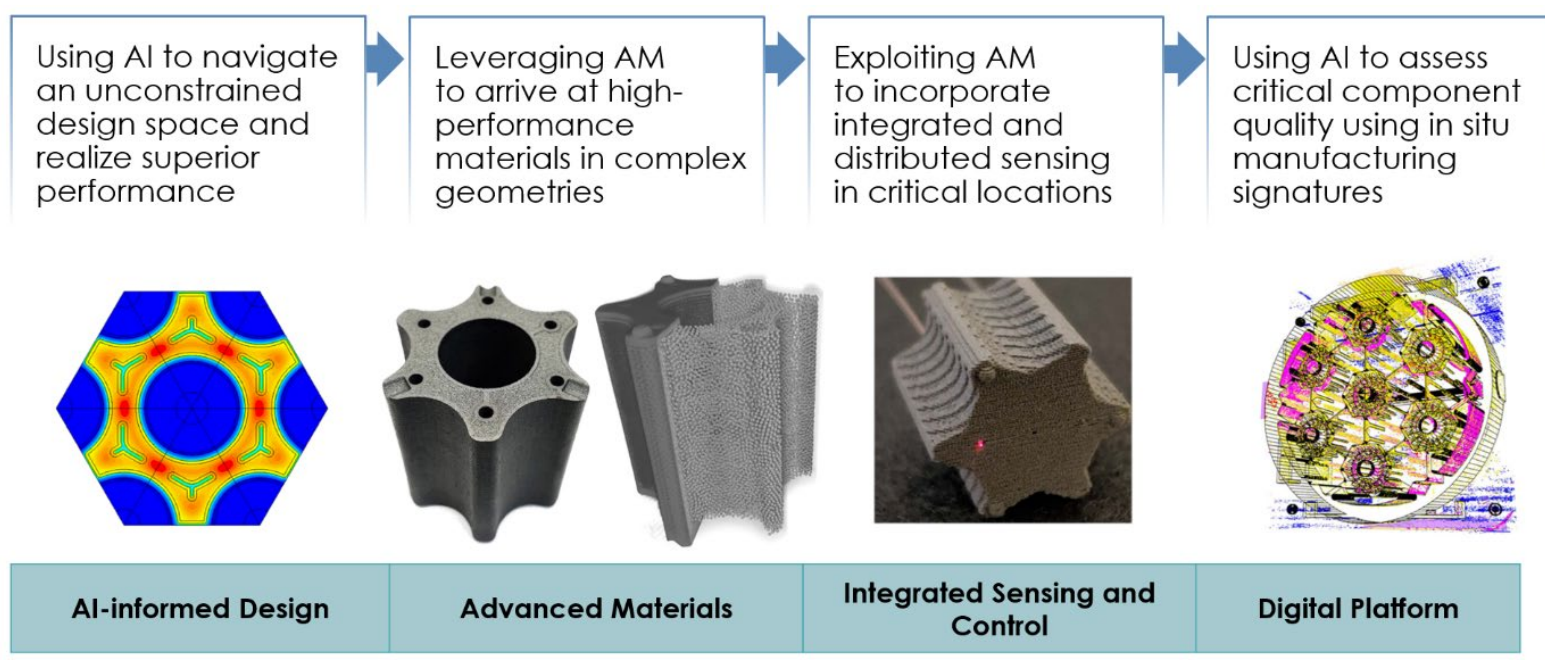

Figure 1. TCR key research and development thrusts.

AM, and AMTs, are used as umbrella terms to cover a broad range of novel and nontraditional manufacturing methods that are just now being introduced to the United States (U.S.) nuclear industry and have yet to be formally standardized (e.g., through nuclear codes and standards, through a submittal, or other processes resulting in U.S. Nuclear Regulatory Commission (NRC) approval/endorsement).

AMTs are of significant interest to both the current operating fleet of reactors and to new proposed reactor designs. To deploy these new AMT-derived parts and components, the quality assurance (QA) requirements and associated regulatory guidance documents are being developed by the NRC with significant industry input from codes and standards organizations (e.g., ASTM, ASME, etc.), trade organizations (e.g., EPRI, NEI), national laboratories (e.g., ORNL), and other research organizations (e.g., universities). For the current operating fleet, traditionally manufactured parts are being identified for

${ }^{1}$ The term artificial intelligence used in this report refers to any computer algorithm which makes decisions which are intended to mimic those made by a human used in tandem with (augmented by) a human expert for performance of safety critical tasks. See the definitions of artificial intelligence and augmented intelligence relay in Appendix A. 
potential replacement with those derived from AM [1]. This approach is being established for commercial reactors with new guidance published that outlines the different processes depending on the application of AMT-derived parts and components [2]. For new proposed reactor designs, a broad spectrum of potential applications is being investigated [3].

Currently, new proposed reactor designs are often hindered by costs associated with the ability to qualify and license components based on the availability of qualified legacy test data, applicable software, and models. Only when the models have been extensively verified and validated is the risk considered acceptable to proceed with plans for fuel and component manufacturing. In addition, the geometries in reactor designs are limited by current manufacturing methods and processes which are engrained in the licensing basis for today's reactors, although the technology is several decades old. The ability to develop a nuclear reactor design and manufacturing process that is integrated with advanced software and additive manufacturing technologies will be transformational for the nuclear industry. This transformation will shift the paradigm to minimize the time to testing and fabrication for unique and advanced components by employing parallel design and manufacturing processes that are tracked and validated using data science. Reactor designs have been limited by nuclear fuel element performance, safety margins, and reactor core configurations, which are a direct consequence of the fuel forms, material compositions, and manufacturing processes. However, the development of efficient, high-performance reactors could benefit from complex geometries to improve thermal energy management, increase safety margins and accident tolerant characteristics, and reduce the overall reactor system footprint. These next-generation nuclear reactor designs operate in all regions of the neutron spectrum at elevated operating temperatures and have a clear lifecycle cost advantage over other energy sources when enabled with unique geometries that advanced manufacturing, and the accompanying data science-driven digital platform, can provide.

Certification and qualification of processes and/or parts produced through advanced manufacturing presents a significant challenge for the nuclear power industry. Gaining regulatory approval of a new manufacturing process that has the potential to affect the performance of components important to system safety is a multi-faceted and time-consuming effort.

In July of 2020, the NRC published a white paper entitled, Advanced Manufacturing Technologies Application Guidance Framework [4]. In it, two approaches are discussed for how components produced by Advanced Manufacturing can be qualified or accepted for their proposed application. These approaches are intended for the current operating fleet with replacement of a system, structure, or component (SSC) with one manufactured from an AMT. These are approaches are discussed in more detail in Section 2.4.

Currently, extensive development and qualification efforts are needed to provide the technical basis for a new technology to be accepted by the NRC. The NRC has promulgated a document entitled, "Draft Advanced Manufacturing Technologies Review Guidelines" which, when finalized will identify the range of information that could be necessary in a submittal seeking approval for the use of an AMT [5]. To supplement the generic guidance provided in this report, NRC is planning to develop separate AMTspecific draft guidelines documents. The draft guidelines documents will address five AMTs that have been identified based on current industry interest:

- laser powder bed fusion (LPBF),

- directed energy deposition (DED),

- powder metallurgy - hot isostatic pressing (PM-HIP),

- electron beam (EB) welding, and

- cold spray.

Of these five AMTs, an ORNL report on LPBF was supplied to the NRC for the purposes of supporting the development of a guideline document [6]. The NRC has also issued its technical assessment of the safety significance of the identified differences between LPBF and traditional manufacturing methods and 
the aspects of LPBF not addressed by codes and standards or regulations [7]. This document discusses the differences between traditional manufacturing and LPBF manufacturing as well as material-specific differences associated with LPBF and traditionally manufactured 316L stainless steel. Specific guidelines are provided for key process parameters (powder quality, build process management and control, postprocessing, etc.). From this, a draft guideline document on LPBF was created [8], and will be discussed at public meeting in late 2021. More information on NRC initiatives is presented in the next section on background.

To date, none of these guideline documents or approaches on AMT certification and qualification have included aspects of a digital platform such as AI, correlations, and connection to ex-situ property data and/or expected component performance. Instead, supplemental testing is encouraged to demonstrate acceptability in areas such as expected component properties and performance, heterogeneity, porosity, residual stress, etc. Given the wealth of in-situ data (e.g., manufacturing data, process parameters, sensor measurement data, etc.) collected as part of the digital manufacturing process, the potential exists to reduce or eliminate the need for any supplemental testing based on an assessment of the application and the applicability and soundness of the in-situ data. The Digital Platform has the potential to transform how concepts of equivalency and expected component performance are measured.

Currently, there is no discussion or pathway for using the data and AI embedded within the Digital Platform to demonstrate equivalency and expected component performance. This report explores how the Digital Platform could integrate with the regulatory framework being proposed by the NRC for advanced manufactured components.

\subsection{OBJECTIVES}

The primary objective of this report is to explore and describe aspects of a performance-based certification process for AMT-derived components (also referred to as SSCs) that takes advantage of digital manufacturing data, AI, and relevant physical test data that is connected via a cyber-physical infrastructure called the Digital Platform. This report does not document a final process or ultimate guide for using the Digital Platform to inform certification, but rather, to propose steps which may be included as part of a future industry or regulatory guidance-type document that similarly views the transformative potential of a Digital Platform.

A second objective of this report is to document an example of the proposed generic, high-level steps for informing AMT-derived component certification through the TCR program.

\subsection{SCOPE}

The scope of this report is discussed in terms of three areas:

1. the types of AMTs,

2. the types of AMT-derived components (or SSCs) and their safety significance, and

3 . the materials of interest.

Broadly, there are over 55 advanced manufacturing methods with potential applicability to the U.S. nuclear industry [9]. While all the methods identified could eventually be employed in fabricating components for the nuclear industry, further evaluation identified sixteen (16) methods that are most likely to be deployed first and most abundantly for the nuclear industry, three of which being listed under the category of additive manufacturing (Binder Jetting, Laser Powder Bed Fusion (LPBF), and Directed Energy Deposition). Current research using these three additive manufacturing technologies are underway at ORNL. The digital platform-informed certification has the potential to be most applicable to these three AMTs. However, the general structure outlined later in this report may be applicable to many, if not all, of the other AMTs. 
The specific materials of interest are also dependent on the SSC and AMT being proposed. The next section briefly describes some of the differences between AMT and traditional materials and why it is important to include materials as part of the scope of any AMT-related report on qualification or certification.

In terms of materials applicable to this report, metals are of prime interest and no metal is inherently excluded. In terms of the TCR example, stainless steel LPBF is presented. Only a single component type is manufactured in this example, which is a short (18 in.) thin-walled cylindrical tube. Since the purpose of this simple example is to showcase the presented steps of using the digital platform, the safety significance is irrelevant or negligible. However, in the future, as the presented steps are developed more as part of more formal industry or regulatory guidance, or as continued research by the U.S. Department of Energy (DOE), real applications could be identified with an increasing level of safety significance as the process matures.

\subsection{AMT VS TRADITIONAL MATERIALS}

The following is a partial list of the more common metals used in AM in various industries [10]:

- Nickel chromium super-alloys yield sturdy, corrosion-resistant metal components used in highstress, high-temperature applications in aeronautical, petrochemical and auto racing environments.

- Cobalt chrome is resistant at high temperatures to corrosion, and when wear is critical, cobalt chrome is often selected as the material of choice.

- Aluminum alloys are selected by the aerospace and automotive industries due to the material's high strength-to-weight ratio, resistance to metal fatigue and corrosion.

- Stainless steel is used in additively manufactured parts in several industries including automotive, industrial, food processing and medical applications due to the hardness, tensile strength, formability, and impact resistance of fabricated parts. Stainless steel is used in applications requiring dense, super-strong, waterproof parts for extreme environments like jet engines, rockets, and nuclear facilities.

- Titanium alloys are used in additive manufacturing to produce industrial components such as blades, fasteners, rings, discs, hubs, condenser tubing, heat exchangers, jet engines, airframes, marine chemical applications, and vessels. Titanium's biocompatibility makes the metal a viable option for medical applications, particularly when direct metal contact with tissue or bone is a necessity.

In conventional manufacturing, the material microstructure is homogenous and uniform throughout the initial ingot and machining does not affect material properties. This results in two important consequences that are frequently overlooked by engineers and scientists accustomed to conventional manufacturing techniques: (1) the material properties of conventionally manufactured components are homogeneous and uniform throughout the component, and (2) samples sourced from the same ingot as the component have material properties statistically indistinguishable from the manufactured component. Neither of these relationships necessarily hold for LPBF. Instead, LPBF component geometry is a variable that affects heat transfer and the effect of the scan strategy on the local microstructure. Component properties such as tensile strength, fatigue strength, and ductility are not uniform throughout the component but instead are functions of geometry. Therefore, obtaining uniform microstructures on components with varying thicknesses is difficult and is an active area of research. The wall thickness and geometry required to observe raster bridging varies with scan strategy and the alloy used. 


\subsection{ACRONYMS AND TERMINOLOGY}

Commonly used terms and acronyms are defined in Appendix A of this report.

\subsection{REPORT ORGANIZATION}

In addition to this introduction section, this report contains additional background material on AMTs, use of AMTs in nuclear applications, and the Digital Platform, which is provided in section 2. Section 3 presents a high-level, generic approach for using the Digital Platform to inform certification of AMTderived components. Section 4 presents an example that applies this high-level, generic approach to a specific example performed through the TCR program. Finally, additional discussion and conclusions are presented in section 5 . 


\section{BACKGROUND}

This section provides a background on the AMT processes, the regulatory environment, and the current status of their use in the nuclear industry.

AMTs encompasses a variety of processes which include AM, also known as three-dimensional (3-D) printing. AM is a process in which a part or component is produced from a digital model by adding successive layers of material to create the object. Decision makers in industry (e.g., automotive, aviation, defense, and medical sectors) are realizing that potentially significant cost savings and reduction of production time can be accomplished using AMT processes. Manufacturing on-site is also made possible by AMTs instead of relying on a distant supplier [11].

AMTs also have the potential to transform the nuclear industry by producing high quality components faster and cheaper for current operating plants and future advanced reactors. AM offers a unique ability to mitigate the nuclear industry's looming supply chain issues while providing an essential flexibility for

tailored component fabrication to support a wide range of emerging advanced reactor designs. In addition, AMT processes make possible the fabrication of components originally provided by vendors that are no longer in business (obsolete parts), which provides needed relief for the economically struggling and aging current operating fleet of nuclear power plants. Potential barriers to utilizing AMT-derived components in nuclear applications include a lack of clarity of regulatory pathways and timely review. Without this clear and timely direction, manufacturers will struggle to develop a technical qualification program for AMT-derived components. Guidance is currently being developed for AMT-derived components. One goal of this report is to demonstrate the potential for the Digital Platform to aid in the certification of AMT-derived components.

\subsection{REVIEW OF SELECT AMTS}

As previously mentioned, the NRC is focusing on five different AMTs (LPBF, DED, PM-HIP, EB welding, and cold spray). Of these five, LPBF and DED are considered as AM processes. Additive manufacturing processes can be single-step or multi-step processes. Single-step operations produce the basic geometric shape and material properties in a single step simultaneously. Multi-step operations produce parts in two or more processes, in which the first usually produces the basic shape of the part and subsequent steps merge the part to the desired basic material properties. Figure 2 provides a simplified diagram for manufacturing metallic parts, distinguishing between single- and multi-step processes. Figure 3 provides an overview of multi-step processing for various AM media. 


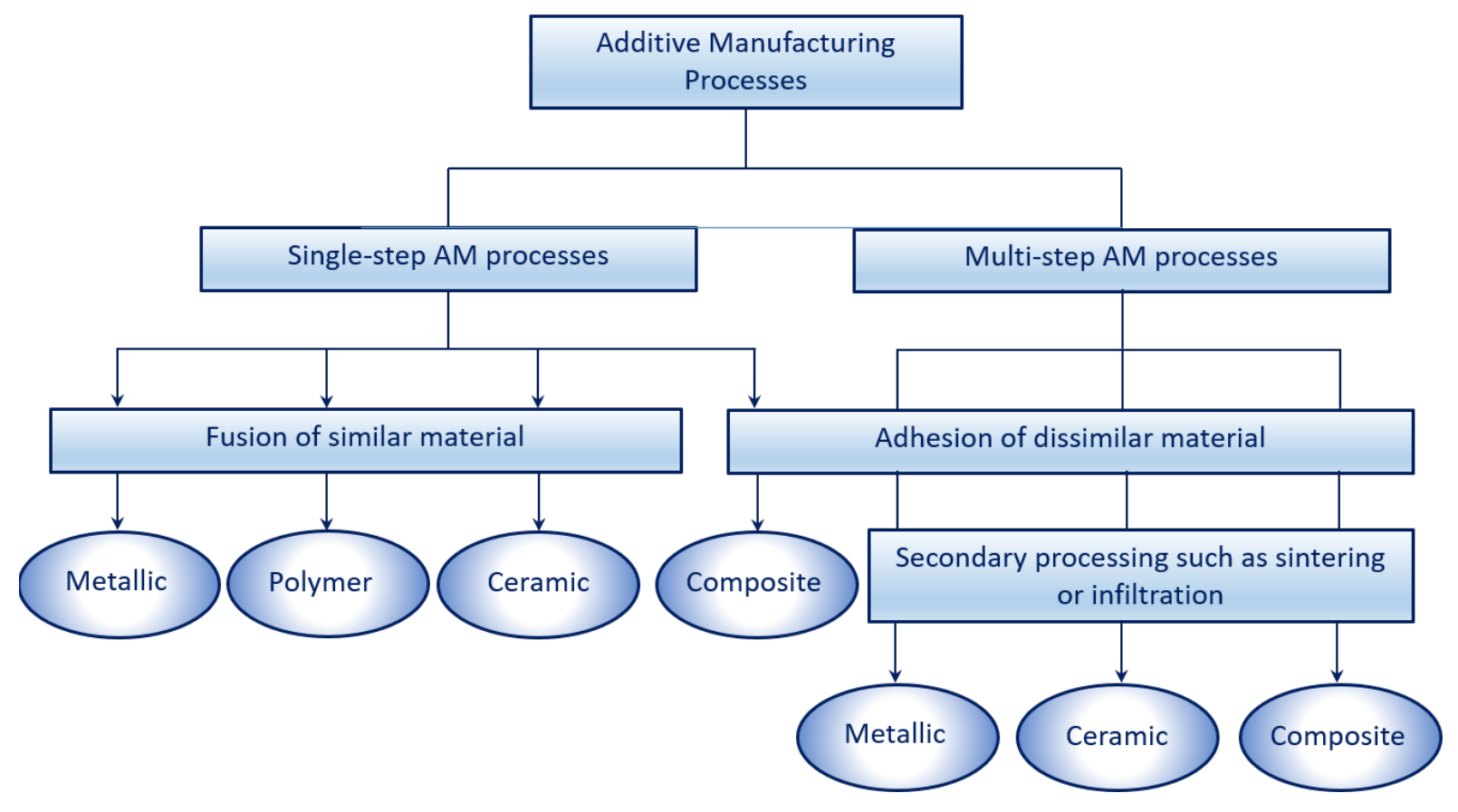

Figure 2. Single and multi-step AM processes [12]. 


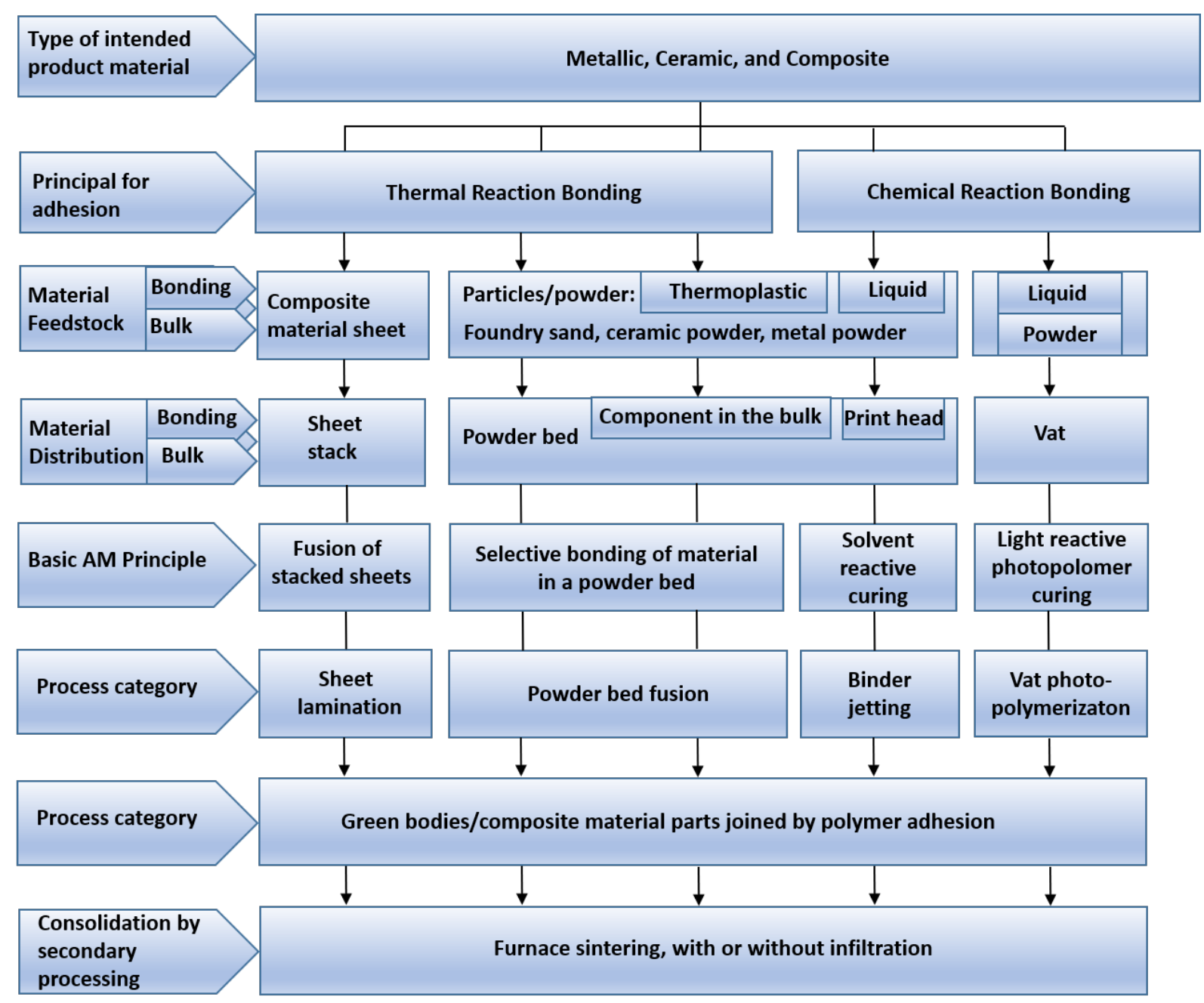

Figure 3. Overview of multi-step processing for various AM media [12].

\subsubsection{Binder Jet}

Binder Jetting selectively binds powder with a solvent-polymer solution to build a low-density green part (Figure 4). Geometric flexibility, feature size, and resulting surface roughness are dependent on the material type and powder size. Ceramics and metals are possible materials. Follow-on techniques for densification are commonly used to meet performance requirements for the part.

The binder jetting manufacturing process is done in five steps: (1) each layer is configured with a specific set of process parameters; (2) a rolling mechanism covers the build plate with a layer of powder; (3) the binder deposition process operates similarly to the ink jet printing process: the print head moves in a predefined pattern over the build plate, depositing binder only where needed; (4) a radiative heating element scans the build plate to dry the binder; (5) once the layer completes, the stage supporting the build plate lowers to the desired layer thickness (typically 50 to $200 \mu \mathrm{m}$ ), and the process repeats until completion of the geometry [13]. 

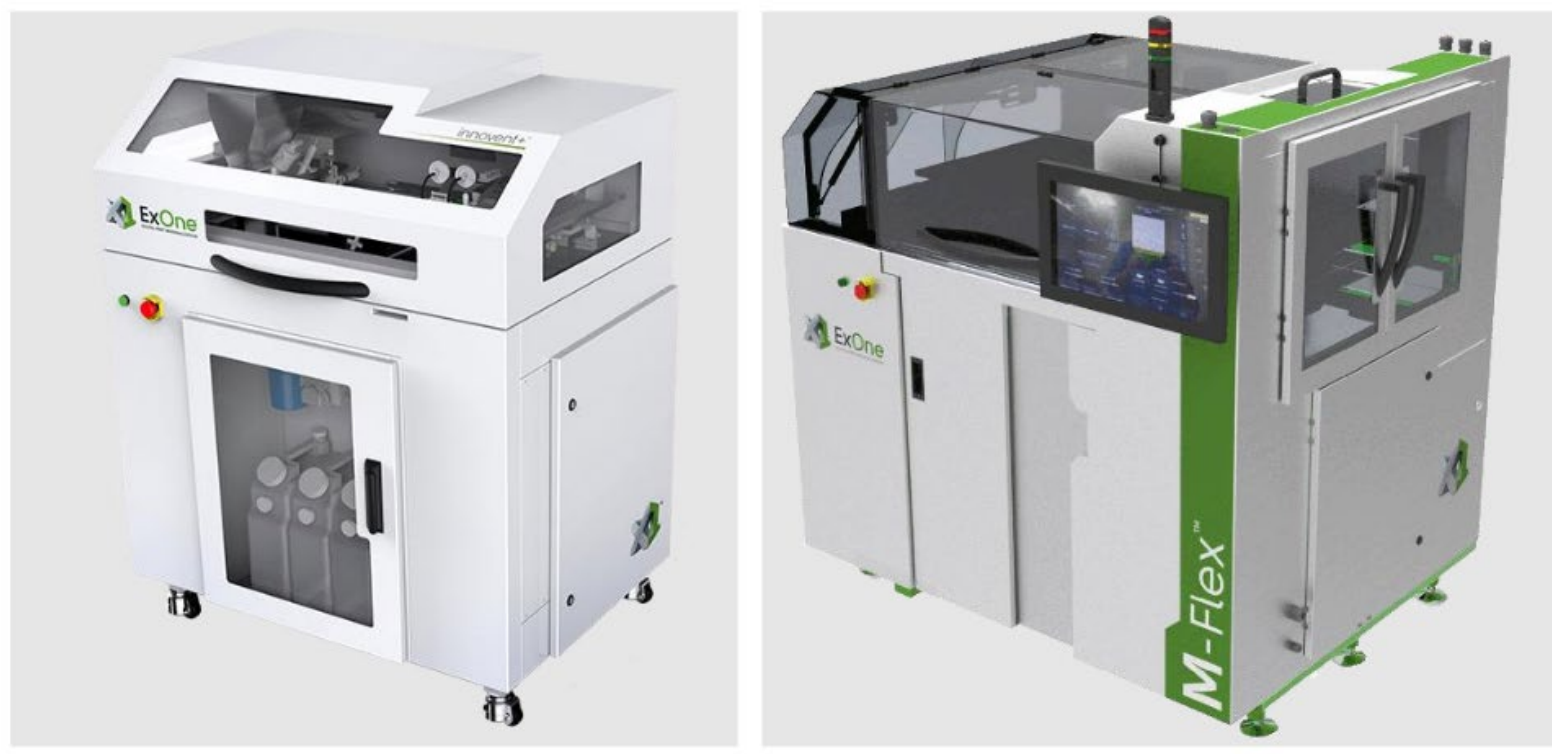

Figure 4. ExOne BinderJet printers [13].

\subsubsection{Laser Powder Bed Fusion}

LPBF melts thin layers (typically 20 to $160 \mu \mathrm{m}$ ) of powder to build parts layer by layer. A 3-D computer aided design (CAD) file of a component is first "sliced" into thin planar layers as illustrated in Figure 5 [14]. Feature sizes and roughness depend on material type and powder size. Powder bed fusion is a common method for additive manufacturing with metals. Follow-on techniques for selective machining are typically implemented according to the performance requirements of the part.
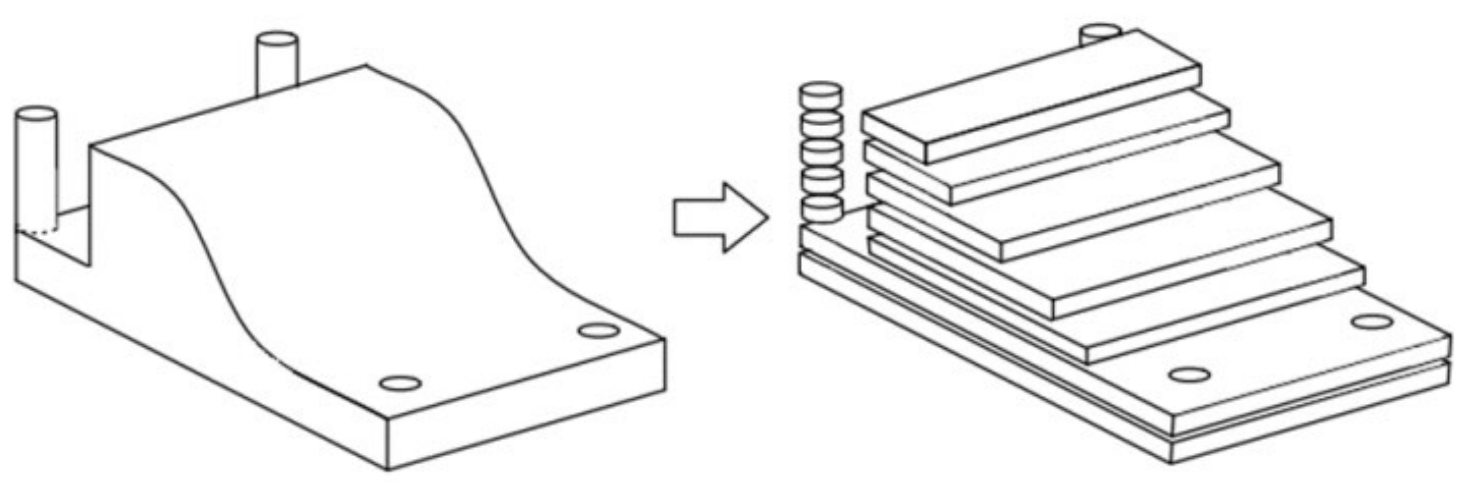

Figure 5. Component slicing [14].

The LPBF manufacturing process (Figure 6) is accomplished in four steps:

1. Each layer is prepared with a specific printing scan strategy and associated process parameters such as laser power and speed.

2. A raking mechanism covers the build plate with a layer of powder.

3. The melting process programmed during step 1 is applied to the layer, 
4. Once the layer is complete, the stage supporting the build plate lowers to the desired layer thickness (typically 20 to $80 \mu \mathrm{m}$ ). This process repeats until completion of the part. This system is equipped with standard sensing technologies to ensure correct mechanical operation. Specific to the M2 LPBF machines, two optional technologies are available to assess the quality of the melting process and to assess the quality of the layer of powder [15].
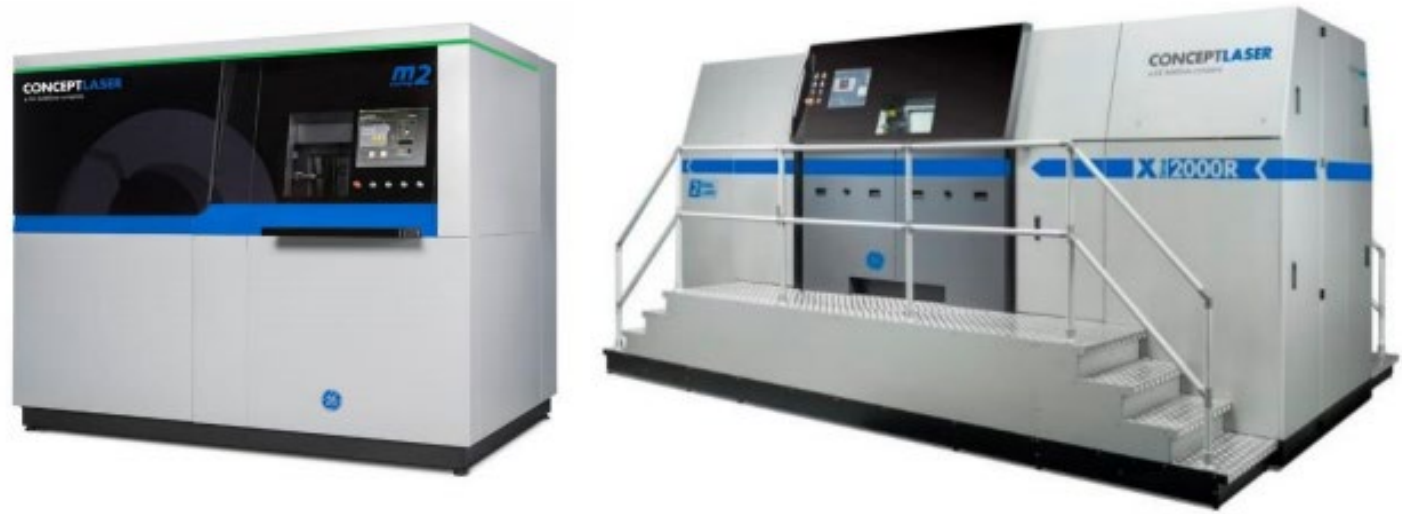

Figure 6. GE Laser Powder Bed Fusion printers [15].

Although LPBF is generally a reproduceable process, quantitative data on part-to-part variability in a production setting, powder feedstock lot-to-lot variability, and machine-to-machine variability is not readily available due to corporate confidentiality of machine manufacturers. Reported material property values for laser powder bed fusion components vary widely in common measurements such as yield strength (YS) and ultimate tensile strength (UTS).

AM presents unique challenges in certification for nuclear power applications such as anisotropic material properties, porosity, underdeveloped process control feedback systems, and reproducibility. Conventional manufacturing also has challenges with variability; however, conventional component variability is generally concerned with geometric accuracy rather than material properties. Casting is the most analogous conventional manufacturing method with respect to material property variability and defects (e.g., porosity).

\subsubsection{Directed Energy Deposition}

Directed energy deposition covers a broad range of materials and processes. Directed Energy Deposition (DED) adds material to a small melt pool that is formed with focused thermal energy to build parts volume by volume. A typical DED machine consists of a nozzle or deposition head mounted on a manipulation system, which deposits melted material (except for blown powder systems) onto a specified surface where it solidifies. The process is similar to material extrusion except that rather than melting and extruding a thermoplastic, an energy source is used to melt and fuse metals to create near net shape structures. The material can come in the form of wire or powder. The energy source can be a laser, electron beam, or wire welding system (metal inert gas, tungsten inert gas). As with additive in general, each process has advantages and disadvantages. For example, the blown powder systems generally have superior surface finish and ability to blend material but are typically slower and more expensive than wire systems. Powders are usually more expensive than wire feedstock and material utilization is generally under $50 \%$. Figure 7 is an image of a wire-fed DED printer at ORNL. Feature size and surface roughness depend on the material feed. Metals are typically used for directed energy deposition. Follow-on techniques for selective machining are commonly used according to the performance requirements of the part. 


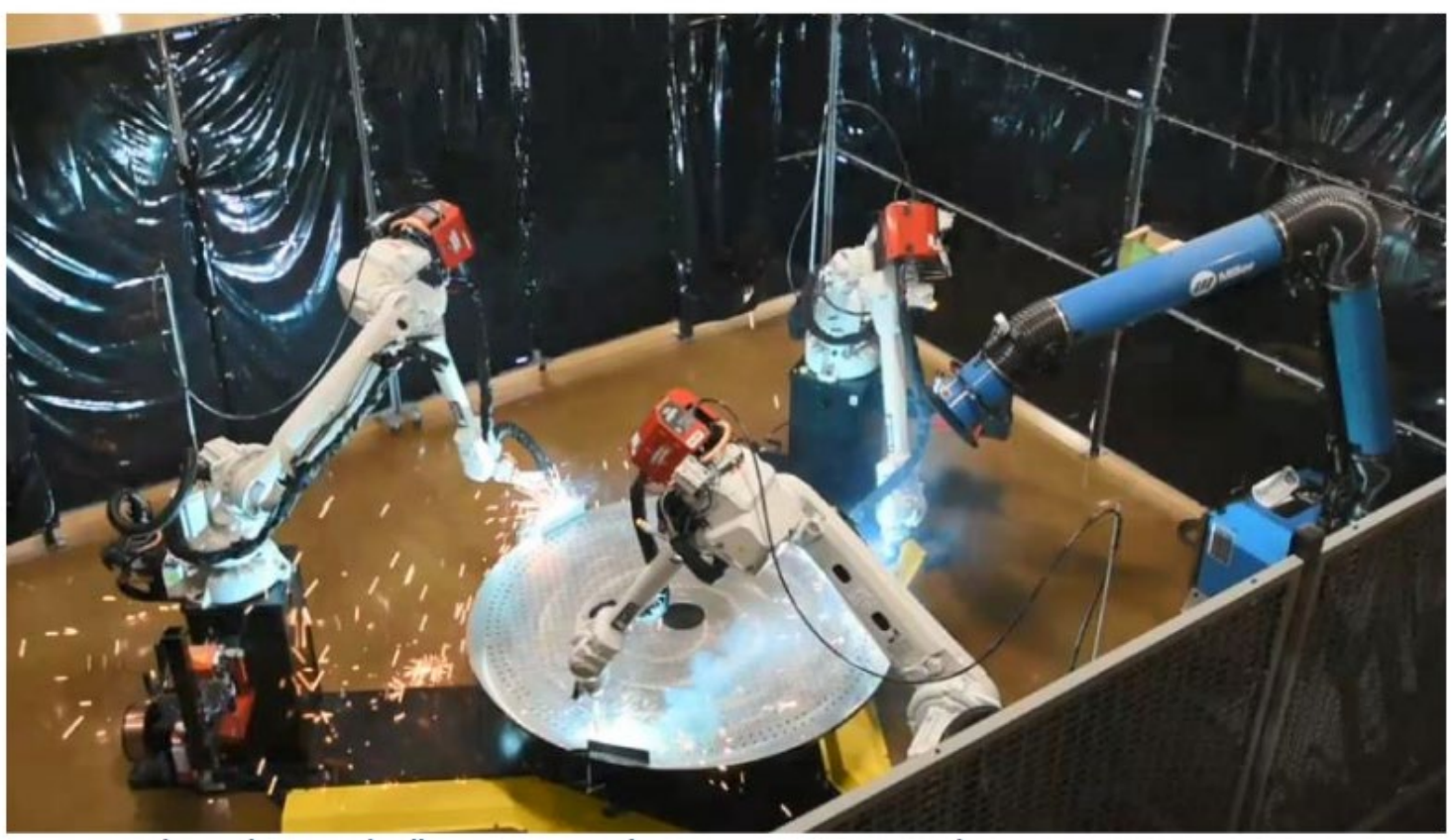

Figure 7. Medusa multi-arc work cell at ORNL

Like LPBF, laser DED is a reproducible process with material properties equivalent or similar to conventional manufacturing, provided that appropriate calibration, technician training, and feedstock tracking is applied. Academic studies have attempted to address the knowledge gap in property variability, but frequently suffer from incomplete reporting, narrow focus, and lack of replicate specimens. Also like LPBF, reported material property values for laser directed energy deposition components vary widely in common measurements such as YS and UTS. Specific properties such as irradiation stress corrosion cracking crack growth rates may only have one or two published journal articles [16].

\subsection{NON-NUCLEAR AMT APPLICATIONS AND QUALIFICATION ASPECTS}

Outside of the nuclear industry, applications of AMT are diverse and, in some cases, commonplace. A thorough review of non-nuclear industry AMT applications is currently being performed, and an ORNL report is anticipated around the same time as this report is published [17].

\subsubsection{SPACE INDUSTRY AND NASA}

For the space industry and the National Aeronautics and Space Administration (NASA), some of the keys to reducing the cost of rocket parts is minimizing the number of components and simplifying system designs. The NASA Marshall Space Flight Center is using AM to produce propulsion systems and other aerospace components to meet NASA mission and industry needs. Marshall teams are testing the characteristics of additively manufactured turbopumps, injectors and other engine components.

In terms of qualification of AM components, NASA has established its own set of standards governing the production of AM parts, NASA-STD-6030 "Advanced Manufacturing Requirements for Spaceflight Systems" [18] and NASA-STD-6033 “Additive Manufacturing Requirements for Equipment and Facility Control." [19] These standards set the requirements for the qualification, maintenance, and calibration activities on AM machines and the foundational process controls for safe implementation and 
qualification of the process. A risk-based approach is used to classify parts based on consequence of failure, structural demand, and AM-associated risks. For higher risk parts, the qualification test program must demonstrate that the part performance and functionality meet the design mission requirements, life factors, and life-cycle capability. In addition to qualification testing, part acceptance is expected to be performed for higher risk AM parts. AM part acceptance is performed by a party other than NASA. The process verifications done throughout the build cycle form the objective evidence required for the part acceptance.

\subsubsection{AVIATION AND FAA}

Like with NASA and the space industry, AM is attractive to the aviation industry due to opportunities for weight reduction, design flexibility, "fail fast/learn fast" prototypes, reduced development time, rapid resolution of supply chain challenges, and cost savings. Many aviation manufacturers are using additive manufacturing to produce replacement parts. Both critical and non-critical parts are being created by AM for engines, fuel nozzles, aircraft door locking parts, etc.

In terms of qualifying these AM parts and components for flight operation, the Federal Aviation Administration (FAA) is responsible for approval of the design and manufacture of civil aircraft, the maintenance programs, and the operational system in which they are used. According to the $2020 \mathrm{FAA}$ report to Congress on Additive Manufacturing, certification of additively manufactured parts fits into the existing FAA regular approval system. The FAA only certifies final products and not the manufacturing process. The FAA has issued AIR100-16-130-GM18 "Engineering Considerations for Powder Bed Fusion Additively Manufactured Parts" [20] and AIR100-16-110-GM26 "ASI Job Aid for Additive Manufactured Parts" [21] that are intended for FAA staff to use to assist in discussions with applicants seeking to obtain certification and to assist inspectors in performing evaluations of facilities using AM. There are also efforts by industry to publish specifications related to materials and the FAA collaborated with the Aerospace Industries Association to issue a report on Recommended Guidance for Certification of AM Components [22]. The report outlines a process that design approval holders should undertake when seeking FAA certification of AM components, specifically those manufactured using powder bed fusion and directed energy deposition.

\subsubsection{MEDICAL INDUSTRY AND FDA}

With the advancements in additive manufacturing, companies are producing both off the shelf and custom or patient-matched devices such as dental devices, surgical implants, and prosthetics. The Food and Drug Administration (FDA) has reviewed more than 100 devices manufactured using 3D printers, which are now available in the market. These include customized patient-matched devices to fit a patient's anatomy including cranial implants and knee replacements [23].

The FDA does not "certify" any aspect of specific medical devices or their production. For AM and nonAM devices, devices are approved using submittals that provide sufficient detail for FDA to be able to determine that the device is substantially equivalent to another similar legally marketed device(s). The FDA classifies medical devices into three classes based on the risk to the patient regardless of the manufacturing process. The Code of Federal Regulations establish requirements for all manufacturers regardless of manufacturing method (AM and non-AM) to establish and maintain quality systems, documentation, and implementation procedures that ensure design requirements are met for higher risk devices. The FDA issued "Additive Manufactured Medical Devices Guidance for Industry and Food and Drug Administration Staff" for the industry and FDA staff proving an outline of the technical

considerations associated with the additive manufacturing processes and recommendations for testing and classification of devices [24]. 


\subsubsection{MILTARY APPLICATIONS}

According to the "Department of Defense Additive Manufacturing Strategy" [25], additive manufacturing "is a versatile technology that provides technical advantages across a range of defense applications in order to build a more lethal and ready force." The Department of Defense (DoD) considers AM a rapid, on-demand, and customizable tool that will modernize the national defense systems, increase material readiness, and enhance warfighter innovations and capabilities. The DoD has at least 80 Military Service depots, maintenance facilities, and field locations that have used AM to produce thousands of parts and tools in an effort to decrease maintenance time, reduce the impact of obsolete parts, and improve existing parts [26]. A few examples of AM are described:

- Internally, the Air Force is focusing on manufacturing low-risk items, such as support equipment, tools, and noncritical weapon system components. This approach will establish a foundation on which to build policies for more critical parts. In 2021, General Electric received Air Force airworthiness qualification in under a year for the first metal 3D-printed, critical jet engine part, an F110 sump cover [27].

- The Army developed a transportable, deployable unit / building called the Rapid Fabrication via $\mathrm{AM}$ on the Battlefield that contains industrial-grade AM equipment. The unit can be used anywhere to improve soldier readiness and return combat-damaged equipment back to service.

- Marine Expeditionary Forces plans to deploy a transportable Expeditionary Fabrication Facility that contains three AM printers to supplement the supply chain and return combat-damaged equipment back to service. The Marine Corps has used AM to produce an H-1 helicopter (H-1) helmet visor clip, reducing the production time from 270 days to 10 days at a cost of $\$ 0.75$ to produce each clip instead of $\$ 300$.

- The Navy has used AM to produce an MH-60R Sea Hawk Helicopter sonar system cover. The AM sonar system cover eliminated corrosion of the traditionally manufactured cover, reduced the lead time from 2 years to 1 week.

Due to a lack of a DoD wide policy, each of the Military Services and Defense Logistics Agency have developed their own AM processes, procedures, and systems. A detailed description and listing of these AM processes, procedures, and systems is being prepared and will be released as part of the ORNL report on the review of non-nuclear industry AMT applications.

As a step towards standardization, the DoD released "Department of Defense Additive Manufacturing Strategy" and DoD Instruction 5000.93 "Use of Additive Manufacturing in the DoD" [28] to establish the program. In addition, the DoD is developing a guidebook that will address training, data management, equipment security, service specific guidance, certifying parts, manufacturing standards and specifications, and final part acceptance. The next step will be for the DoD to develop Service Directives with prescriptive guidance tailored to customer, application, and environment.

\subsection{NUCLEAR CODES AND STANDARDS}

Several organizations have undertaken the task of developing standards in various sectors of AM. The need for an overarching coordination of efforts was recognized by America Makes and the American National Standards Institute resulting in formation of the America Makes \& ANSI Additive Manufacturing Standardization Collaborative (AMSC) to coordinate and accelerate the development of industry-wide additive manufacturing AM standards and specifications. While writing standards is not the purpose of the AMSC, the major goal is encouraging the development of a consistent, non-contradictory set of standards.

The methodology of the effort was to identify current gaps in the current body of standards, recommend solutions to closing the gap, and assign a suggested priority (high, medium, and low). Thus far, 93 gaps have been identified in the technology as it stands currently. The gaps are in the areas of design, process 
and materials, qualification and certification, nondestructive evaluation, and maintenance. Of that total, 18 gaps/recommendations have been identified as high priority, 51 as medium priority, and 24 as low priority. Additional research is recommended for 65 identified gaps [11].

Recognizing a need for codes and standards to support deployment of AM components in nuclear and other industries, the American Society of Mechanical Engineers (ASME) has formed various committees and task groups (TGs) to develop requirements for use of AM for boiler and pressure vessel applications. These include the ASME's Board on Pressure Technology Codes and Standards and Board on Nuclear Codes and Standards Special Committee on Use of Additive Manufacturing for Pressure Retaining Equipment to develop guidelines for construction of pressure retaining equipment using AM, ASME Section III TG on Advanced Manufacturing to develop rules for the fabrication of Section III components using advanced manufacturing processes and TG on Division 5 AM Components to develop approaches to qualify AM components for elevated-temperature nuclear construction. Recently, ASME issued Pressure Technology Book (PTB)-13-2021 "Criteria for Pressure Retaining Metallic Components Using Additive Manufacturing" [29] to provide criteria for construction of pressure retaining components using the AM powder bed fusion process.

For DOE nuclear facilities, and the TCR program, QA requirements emanate from 10 CFR 830, Subpart A, "Quality Assurance Requirements" and DOE Order 414.1D, "Quality Assurance" which requires the use of NQA-1-2008, "Quality Assurance Requirements for Nuclear Facility Applications" including the NQA-1a-2009, Addendum (NQA-1-2008/9a). Additionally, the program implements NQA-1-2008, Part IV, Subpart 4.2, "Guidance on Graded Application of Quality Assurance for Nuclear Related Research and Development," as the guiding document to grade the application of quality requirements on a risk basis for nuclear research activities, future work phases as the program progresses, and the nature of the planned and potential uses of the milestone deliverables.

\subsection{NUCLEAR REGULATORY COMMISSION INITIATIVES}

To address uncertainties related to AMT, on January 4, 2018, the Executive Director for Operations issued a memorandum to all NRC staff that acknowledges that the introduction of "new and novel technologies" in the nuclear industry will challenge the current regulatory framework and that, without changes in the regulatory approach, licensees have indicated that they will be unwilling to initiate plant modifications. In response the NRC issued "United States Nuclear Regulatory Commission Action Plan for AMTs, Revision 0" on January 25, 2019 and subsequently revision 1 on June 22, 2020. As part of the plan, the NRC issued draft NRC “AMT Application Guidance Framework" in July 2020. The draft framework provides a starting point for discussion between the NRC and stakeholders on potential guidance regarding the use of Advanced Manufacturing Technology. The framework describes, at a high level, a review philosophy and approach to guide NRC licensees and staff with a new AMT application. Currently there are two conventional NRC paths to demonstrating that an AMT component is acceptable and will fulfill its intended function:

1. equivalency approach, attributes of the AMT component meet or exceed the original design and performance requirements. (e.g., equal to or greater than tensile, yield, fracture toughness, SCC resistance).

2. engineering design modification, provide technical justification for changing existing requirements. For example, the original material provided significant margin compared to what is necessary for the component to meets its intended function.

The framework discusses several traditional regulatory pathways that could be followed to implement an AMT manufactured structures, systems, and components (SSCs) depending on its safety-significance and governing regulatory requirements. These pathways include the 10 CFR 50.59 process, submitting a license amendment (technical specification change, etc.), requesting an alternative to a regulatory 
requirement (e.g., 10 CFR 50.55a(z)(1) or (2)), or rulemaking. ASME code cases could provide a path for generic approval of certain AMTs. In addition, NRC approval of topical reports could lessen the burden on applicants seeking to use AMT's.

Review of an AMT-manufactured SSC should only focus on those unique attributes associated with AMT qualification and performance compared to conventionally manufactured SSCs that may affect the SSC's capability to perform its intended functions and meet the intended design requirements. For example, if the AMT-manufactured SSC has different defect characteristics and density than the conventionally manufactured SSC, and these defect characteristics affects cracking susceptibility, then the effect of this difference in cracking susceptibility should be considered when analyzing the AMT SSC (assuming that crack susceptibility has the potential to affect the performance of the SSC to perform its intended safetyrelated function).

Currently, the NRC is in the process of drafting technical and regulatory guidelines for five different AMTs:

- laser powder bed fusion (LPBF),

- directed energy deposition (DED),

- powder metallurgy - hot isostatic pressing (PM-HIP),

- electron beam (EB) welding, and

- cold spray.

Of these five AMTs, a specific draft guidelines document for LPBF has been completed and was discussed at a public meeting held on September $16^{\text {th }}$. These five AMTs, as well as potentially other AMTs, will serve as input to a draft generic guidelines document for AMTs. This roadmap is illustrated in Figure $8[30]$. 


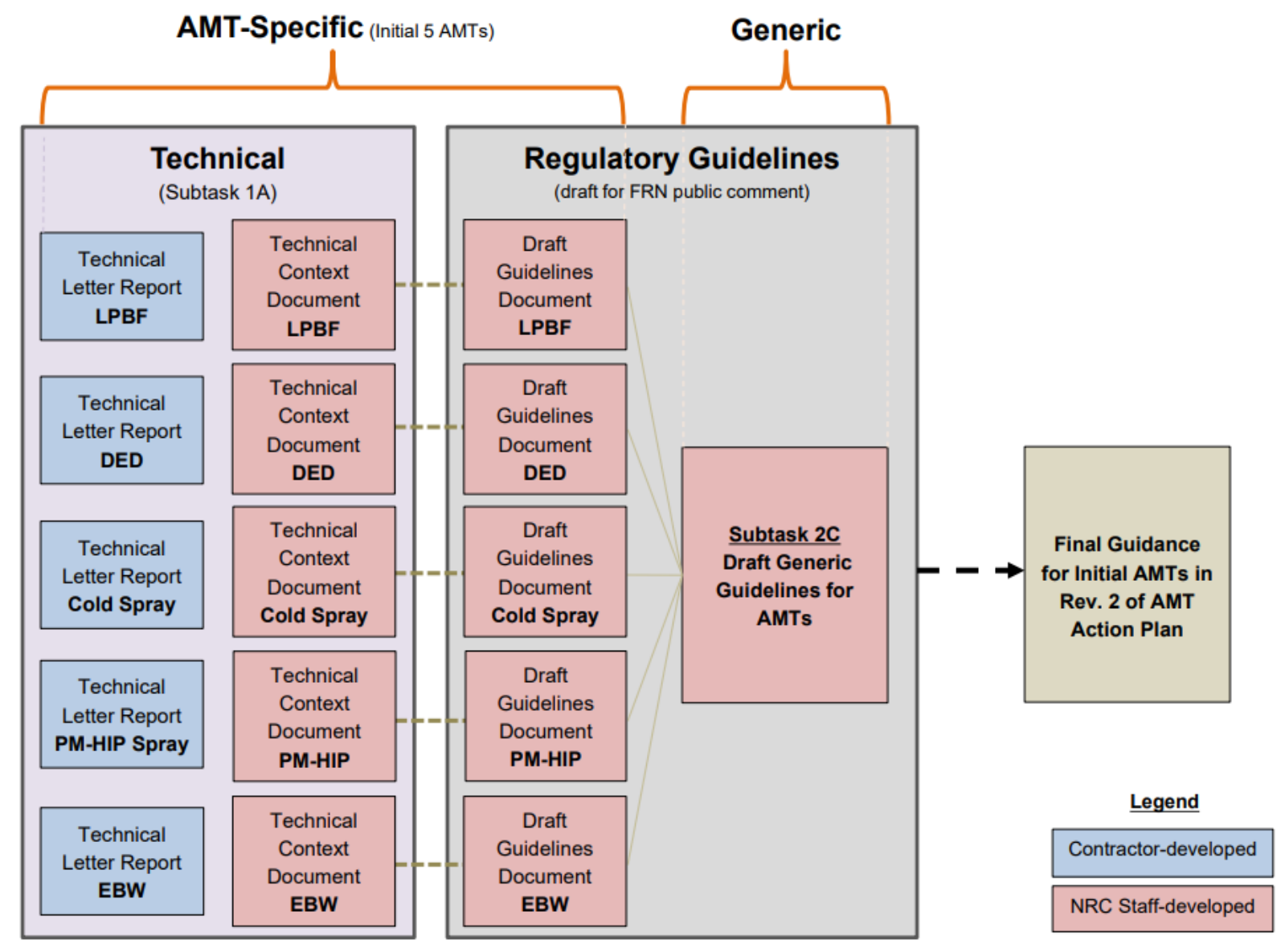

Figure 8. NRC AMT action plan flow chart [29]

Within Figure 8, box for Subtask 2C, "Draft Advanced Manufacturing Technologies Review Guidelines" has been drafted for public review and comment. This document will provide guidelines for NRC staff reviewing submittals requesting the use of AMTs including techniques and material processing methods that have not traditionally been used in the U.S. nuclear industry or that have yet to be formally standardized by the nuclear industry or otherwise endorsed. These guidelines will identify the range of information that could be necessary in a submittal seeking approval for the use of an AMT which could include such things as the maturity of the AMT in the codes and standards arena, prior precedent, and the safety and risk significance of the intended use of the AMT. The guidelines may also address the use of new materials (e.g., of alloys not previously approved through the American Society of Mechanical Engineers (ASME) for nuclear use) and of materials for new or advanced reactors. Figure 9 shows a flowchart with the elements that could support a submittal requesting approval for the use of an AMT. 


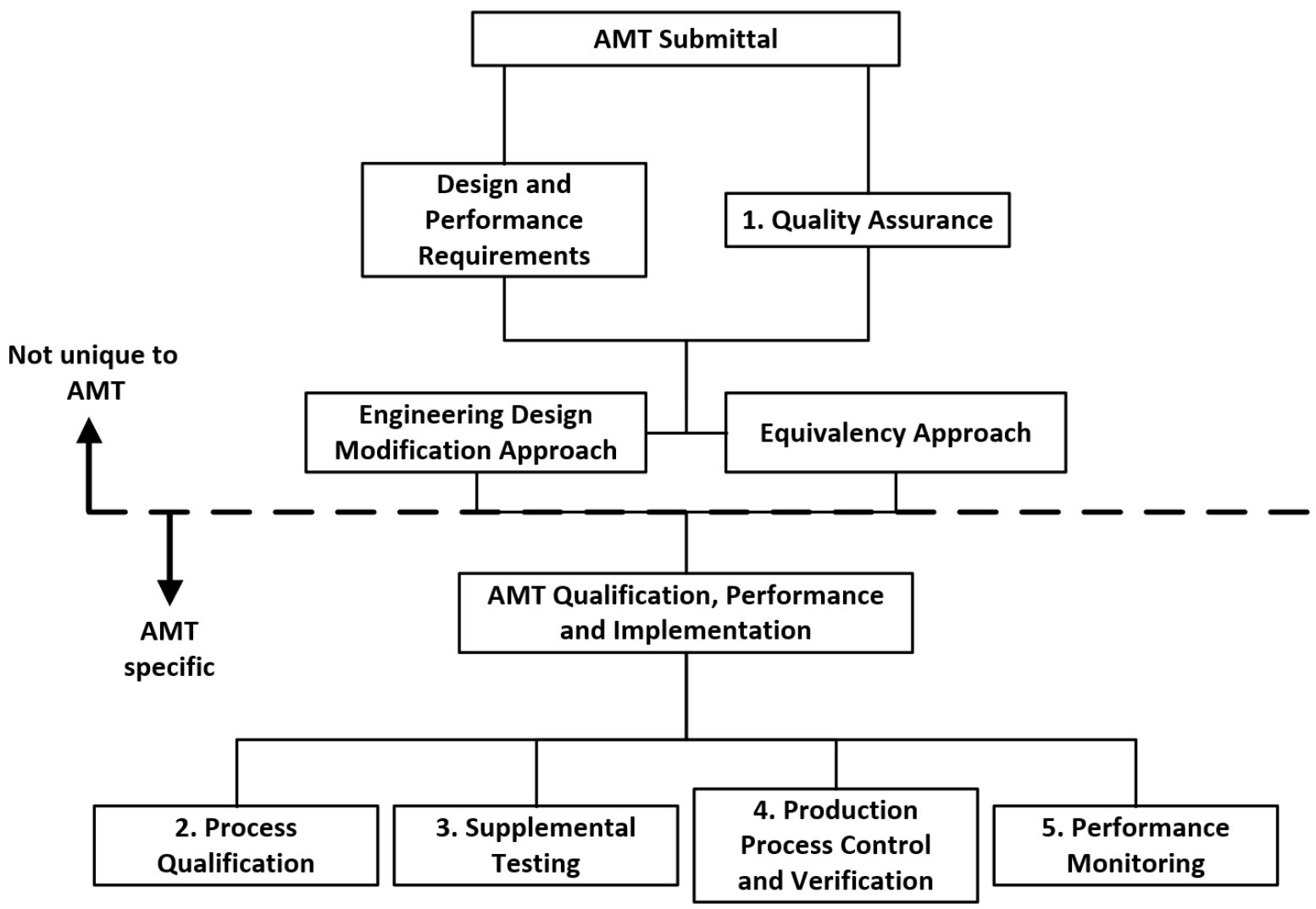

Figure 9. Draft AMT elements required for regulatory review and approval [5]

Five of these elements (numbered 1 to 5 in the figure) are directly applicable to this document. Item 1, Quality Assurance, is not AMT-specific except the document's Appendix A requirement to "identify the QA provisions for all novel or unique aspects of the manufacturing or implementation of the AMT. Elements 2 through 5 are AMT-specific and may require different levels of detail depending on such things as the AMT being proposed, experience in producing quality parts for nuclear or non-nuclear applications, usage of ASME-approved code cases, and safety significance of the intended application.

\subsection{OTHER NUCLEAR INDUSTRY AMT INITIATIVES}

The Electric Power Research Institute (EPRI) along with several industrial partners, has been developing a technical "data package," for manufacture of 316L stainless steel components using laser powder bed AM [31]. The components produced under the project via LPBF include pipe flanges, pipe tee sections, and valve bodies.

Efforts by major commercial nuclear vendors and suppliers to develop and deploy AMT for nuclear components are being supported by intense R\&D, testing and qualification by the U.S. Department of Energy, National Laboratories, and others. An example is the DOE Transformational Challenge Reactor program.

\subsubsection{Transformational Challenge Reactor (TCR) Program}

ORNL's TCR program is sponsored by the DOE's Office of Nuclear Energy to develop the information, processes, and tools to facilitate expansion of additive manufacturing into advanced nuclear energy systems. Previously, the focus of the program was to manufacture and test a nuclear core using additive 
manufacturing while collecting as-built (in-situ) data in a new digital platform that leverages machine learning, materials science and data science technologies to create virtual models for quality inspections of manufactured parts. This technology will also allow fabrication of intricate parts which is not possible with traditional technologies. A clear demonstration of this capability is in the fabrication of TCR fuel elements (Figure 10), which were designed and manufactured to support the demonstration, although the capabilities now also support TCR's revised focus on the four thrust areas.

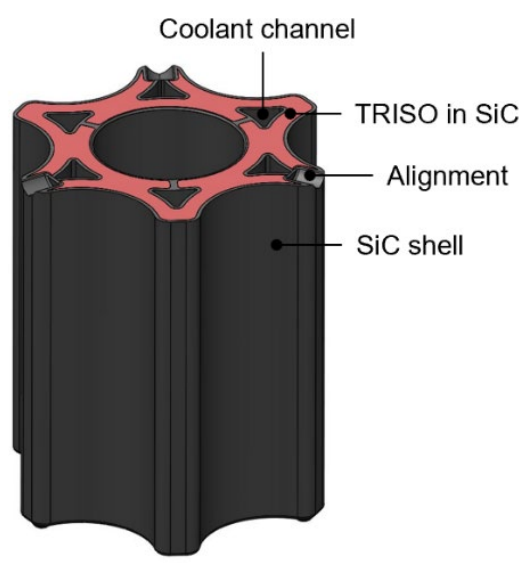

Figure 10. TCR fuel element

The fuel element is composed of a 3-D printed (binder jet) silicon carbide ( $\mathrm{SiC}$ ) shell which is then filled with loose tri-structural isotropic (TRISO) particles. The TRISO-filled shell is then filled with loose SiC powder and the whole element undergoes chemical vapor infiltration to densify the SiC and solidify the element. Coolant channels, alignment divots, and other features are products of 3-D printing and no machining or other post-processing subtractive operations are necessary. A representative fuel element/or fuel assembly is shown in Figure 11.

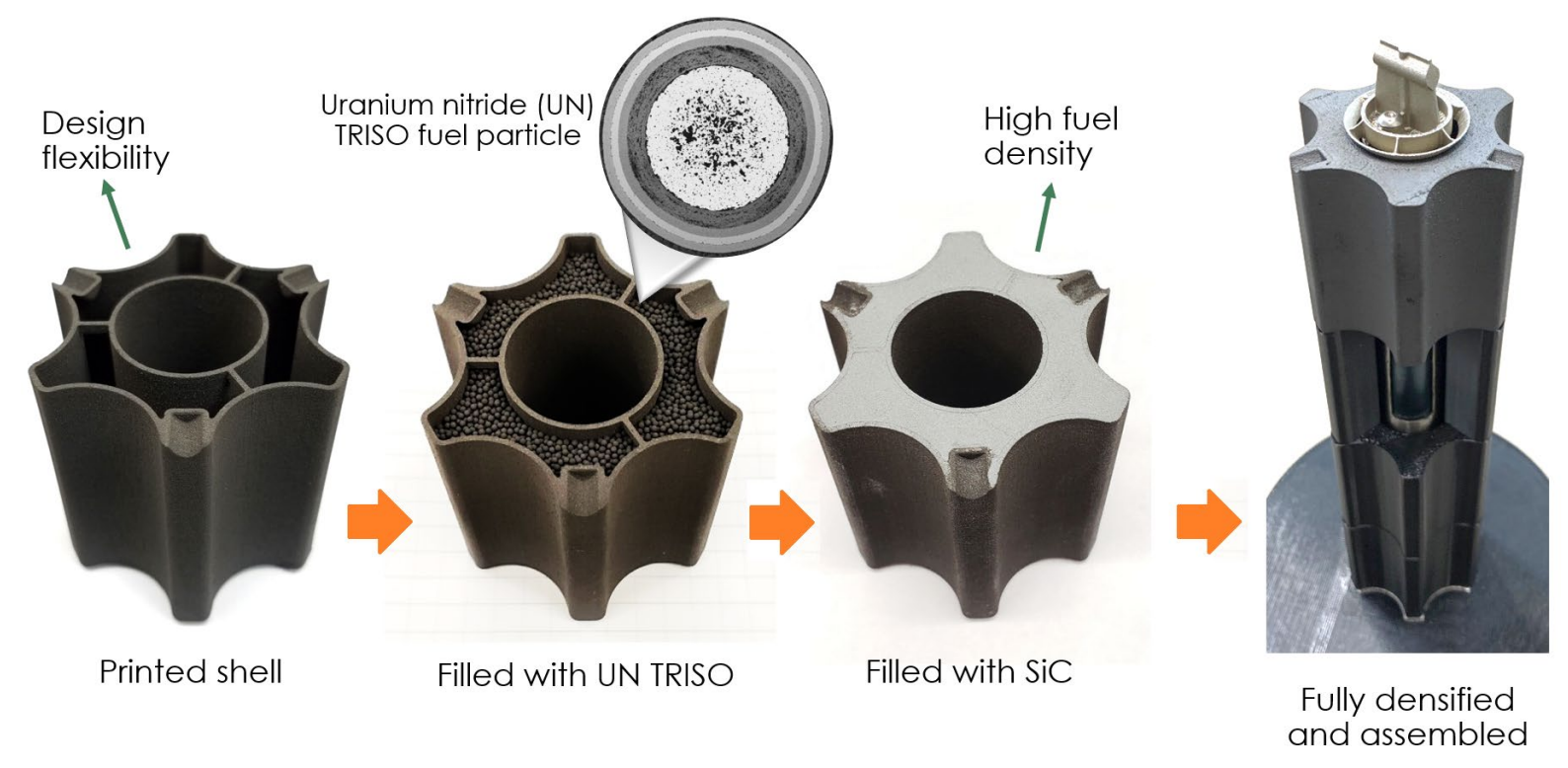

Figure 11. Representative TCR fuel manufacturing phases 
In addition to the fuel, other reactor core internal vessel structures such as the core baffle and support plates are also being printed by LPBF.

\subsubsection{AM Components in Operating Commercial Reactors}

Recently, the TCR program partnered with the Tennessee Valley Authority (TVA) and Framatome Inc., to additively manufacture nuclear safety-related components and insert them into an operating nuclear reactor for three full cycles (six years) [33]. The components were four channel fasteners used for the fuel rod assembly, which were installed in TVA's Brown's Ferry reactor core in April 2021. This represents two first-of-a-kind demonstrations:

1. the first-ever additively manufactured safety-related parts/components to go into a nuclear reactor, and

2. the first physical parts that have "digital twins," or exact virtual models, created using TCR's advanced monitoring and artificial intelligence techniques while being manufactured.

The components will be removed from the reactor in April 2027 and returned to ORNL for further characterization and testing.

Additionally, in spring 2020, Westinghouse installed a 3D-printed thimble plugging device at Byron Station, Unit 1, made of AM 316L stainless steel [32].

\subsection{DIGITAL PLATFORM AND ARTIFICIAL INTELLIGENCE}

A fundamental thrust of the TCR program is the development and demonstration of a new advanced manufacturing paradigm which will produce parts qualified for service in nuclear systems in part by leveraging analytics driven by augmented intelligence relay (AIR) and the concept of a digital twin. The cyber-physical infrastructure which supports this approach at the MDF is referred to as the Digital Platform (DP). The DP provides design input to the 3-D printers in the form of CAD, a robust computing, data storage, and networking capability; instrumentation for recording in situ processing information; details of post-fabrication treatment (e.g. annealing, wire electrical discharge machining, chemical vapor infiltration (CVI), scanning electron microscopy, tensile testing, and purchasing a component from a supplier) and equipment for measuring and characterizing the end product. To paint a full picture of the success (or failure) of a given 3D printed build, additional information such as feedstock utilization, printer calibration timelines, and printer maintenance timelines must also be captured by the DP. One aspect of the DP is a searchable database storing machine-readable metadata and linking to all the collected in situ and post-build characterization data. This information is accessible via a web interface, referred to as the Digital Tool (DT), which allows observation of each component's data throughout the entirety of its manufacturing and characterization process.

The totality of the data collected during manufacturing comprise the digital thread - the basis for constructing a digital twin computer model of the reactor components. A digital twin is a virtual representation of a physical object or system (its physical twin) across its lifecycle, using real-time data to enable understanding and to model how physical assets will perform under certain conditions, assist in monitoring the fabricated part's performance, and enable qualification in real time. Figure 12 is a partial graphical depiction of the digital thread under development at the MDF.

To maintain scalability, every manufacturing process is broken down into a sequence of operations. The digital thread of a manufactured part is then a collection of all the operations which went into the fabrication of the part. The operations associated with fabrication of parts vary greatly. Typical operations include additive manufacturing (e.g., laser powder bed fusion), subtractive manufacturing (e.g., wire electric discharge machining), post-printing treatments (e.g., curing and de-powdering), metrology, and characterization. In addition to the operations that act directly on a part, other operations 
associated with fabrication of a part may include maintenance and calibration records, powder particle size measurements, changes to the printer configuration, etc.

Prediction of reactor-relevant part properties based on in situ data collected during the AM process is accomplished in part by utilization of artificial intelligence (AI) algorithms which ingest collections of digital threads to identify correlations between in situ data and part properties. Importantly, the prediction of part properties is accomplished through a relay of AI algorithms, with each interface between the algorithms being a checkpoint for human inspection to ensure that the subsequent $\mathrm{AI}$ is pointed in the correct direction. This approach is essential to consume the highly unstructured, multi-faceted, and high dimensional in situ sensing data and to successfully link it to part property measurements without requiring the performance of a prohibitively large number of ex situ characterization experiments.

In general, AI algorithms can be loosely separated into four overlapping categories referred to as descriptive, diagnostic, predictive, and prescriptive (Figure 13). Descriptive AI is used to analyze raw data, for example segmenting powder bed images and identifying process anomalies. Diagnostic AI summarizes large datasets and presents them to a human user or another algorithm. A diagnostic AI might flag certain layers of an additive manufacturing operation for closer inspection by a human or it might decide on an autonomous process intervention to attempt to correct a detected defect. A predictive AI seeks to predict part properties (e.g., fracture toughness) based in-situ data, process parameter information, and part geometry. Demonstration of a predictive AI is an end goal of the TCR program. Finally, a prescriptive AI would autonomously modify a part design to improve the predicted performance; this class of AI is beyond the scope of the TCR program but is the ultimate goal for the DP.

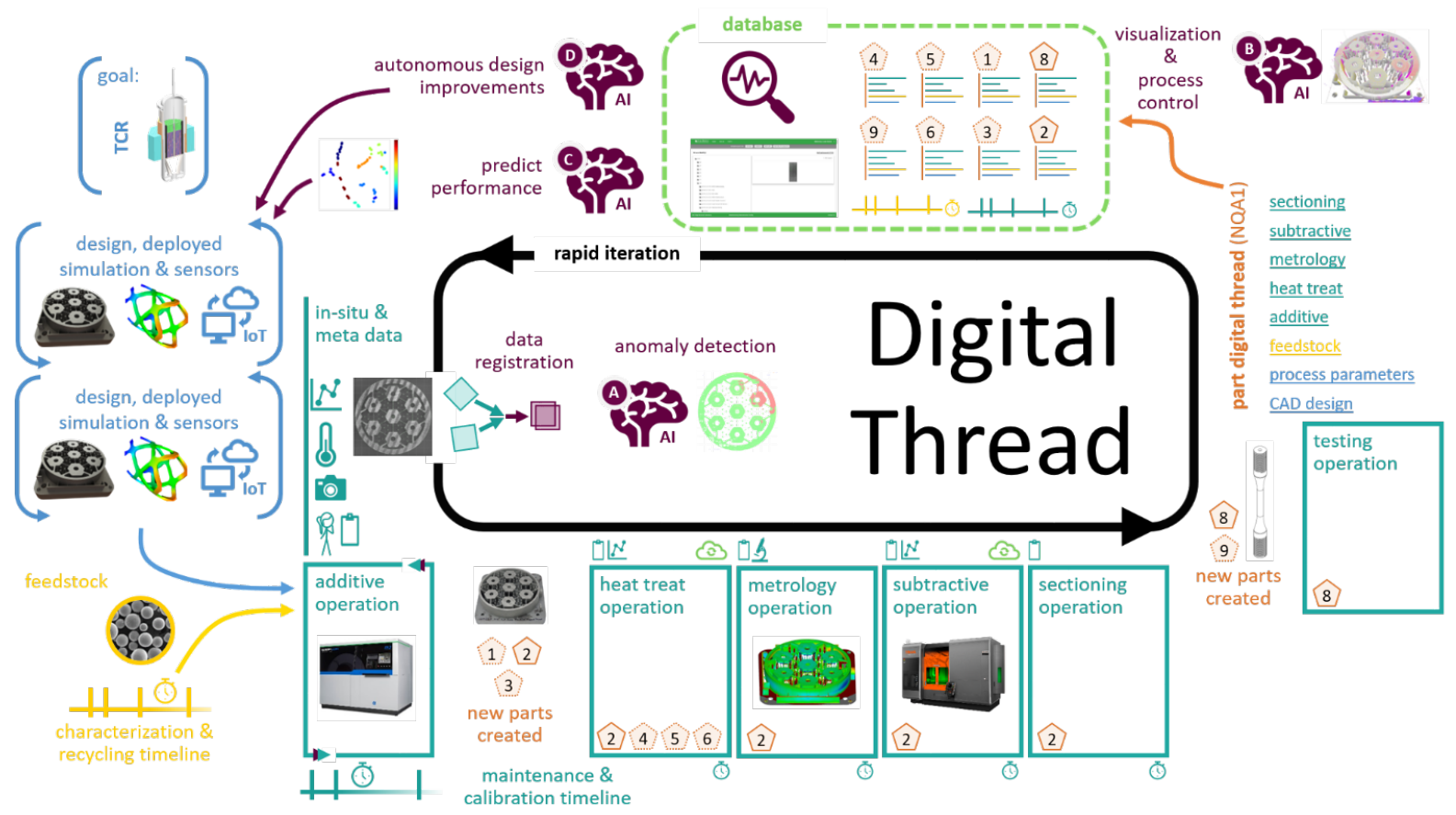

Figure 12. A Graphical Representation of the Information Contained within a Digital Thread of an Additively Manufactured Component 


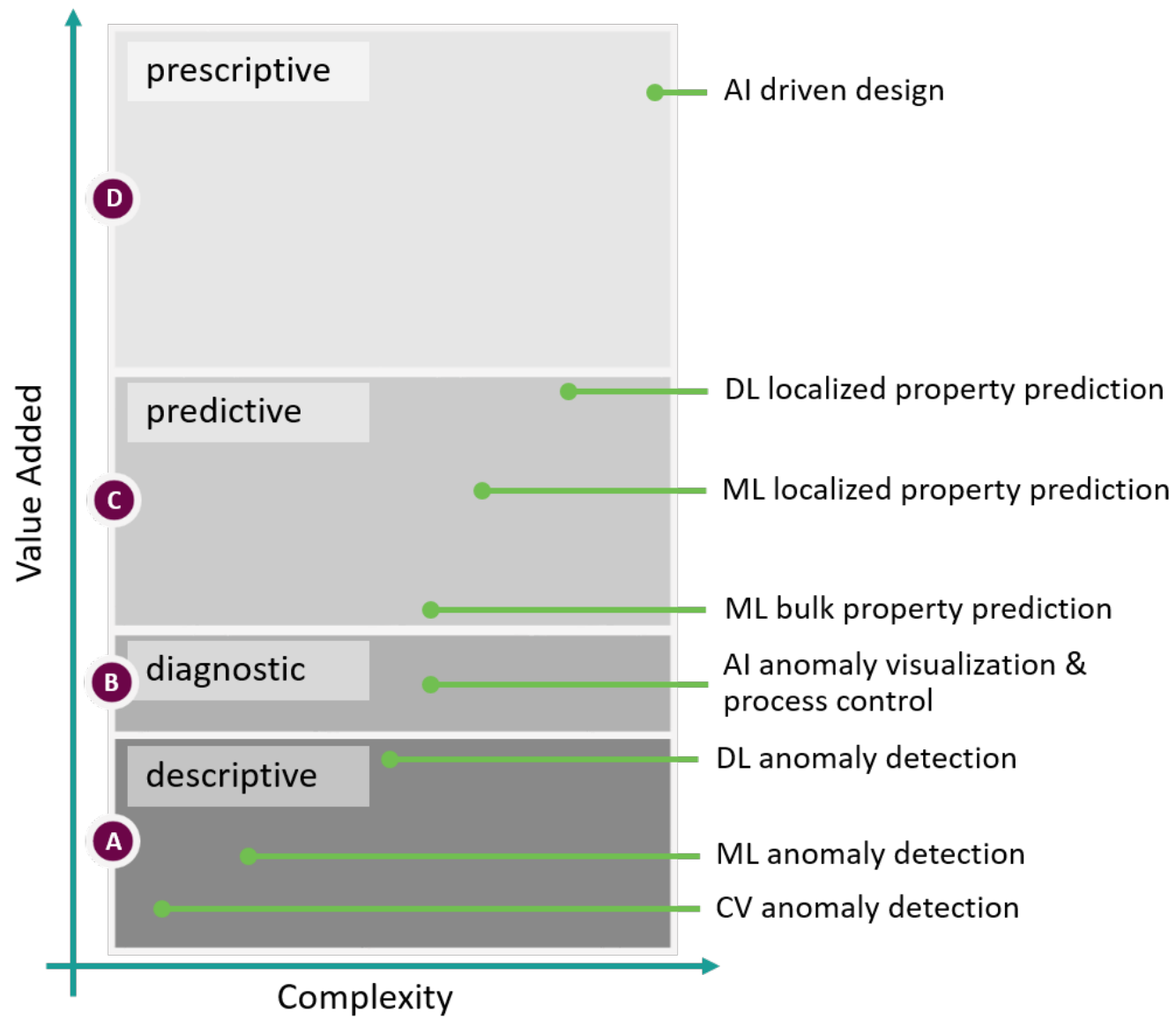

Figure 13. The Approximate Relative Value and Complexity of the Different Types of AI Algorithms 


\section{APPROACH TOWARDS DIGITAL PLATFORM INFORMED CERTIFICATION}

Recognizing that the NRC has proposed draft guidelines for AMT submittal, the digital platform has the potential to reduce or eliminate some component level testing in favor of in-situ data for which AI correlations were developed that ensure equivalency with a non-AMT or traditionally manufactured component. The proposed approach outlined in this section uses the NRC draft guidelines as starting point with modifications which would enable the use of the digital platform as part of the certification process. Additionally, the proposed process contains additional description about industrial requirements and program goals that may go beyond the need for regulatory review. However, they are viewed as essential for maintaining purpose and direction for the overall certification process. The proposed process is illustrated in Figure 14.

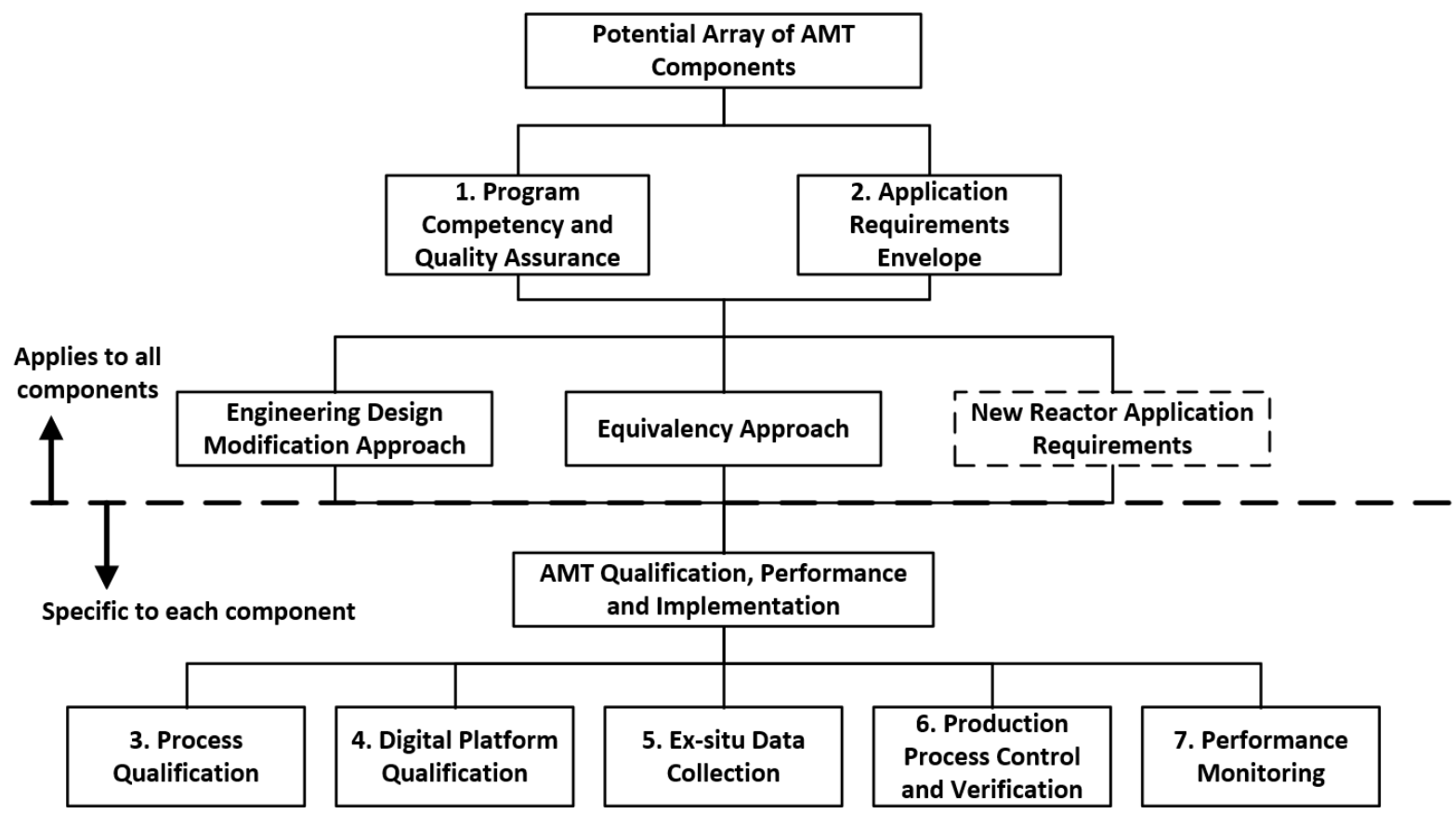

Figure 14. Proposed Approach Towards Digital Platform Informed Certification

This proposed approach and figure is described in the following outline.

- An array of AMT-derived components is desired and documented accordingly in steps 1 and 2, which are described later.

- For an array of components derived from AMTs, a single AMT submittal would likely include two steps:

1. If it is the first component produced through the proposed approach, all steps above the dashed lined would be performed. For successive AMT-derived components which meet certain requirements, the steps above the dashed line would only need to be referenced.

2. The steps below the dashed line would be performed or referenced depending on certain requirements, for each AMT-derived component. 
- Step 1, program competency and quality assurance (including software quality assurance), is performed in accordance with all applicable regulatory requirements and standards and is essentially identical to that presented in the NRC's draft AMT guidelines. However, this specifically includes program goals and program capabilities which are essential to developing and using the digital platform.

- Step 2, application requirements envelope, is where all plant design, safety, and other performance requirements are defined for each component that is to be produced and certified through the proposed process. This then frames the boundary for which components are to be produced with their predicted performances by the digital platform. It also frames the boundary for which ex-situ, physical testing is required to train the machine learning piece of the digital platform.

- Once the array of AMT-derived components and their requirements are understood, the specific qualification approach can be selected, if the application is for the current fleet, engineering design modification or equivalency can be used. However, for a large array of potential AMTderived components, as would be the case for a new reactor application, the specific licensing processing and its requirements would need to be considered.

- Step 3, process qualification, is essentially the same as that documented in the NRC's draft AMT guidelines. In this step, the specific machines, hardware, materials, process parameters, postprocessing, and other manufacturing process steps are defined and held to applicable ASME, ASTM, or other codes and standard requirements.

- Step 4, digital platform qualification, is one of the new elements added, along with ex-situ data collection. This is the cyber-physical infrastructure that collects in-situ build data, maintains, and correlates component performance with collected ex-situ data. There are many pieces to the digital platform, which is described in section 2.6, that may have their own quality assurance steps and procedures. For example, it is anticipated that the developed software used to collect data and interface with designers and potential regulators will adhere to all applicable standard nuclear software quality assurance requirements (e.g., NQA-1).

- Step 5, ex-situ data collection, this is the set of all physical testing required to train the machine learning component of the digital platform to be able to predict or correlate component performance with in-situ data (i.e., the manufacturing build, process, meta, and other data). The requirements here are principally set by the application requirements envelope. For example, if the component performance over its service life is driven by mechanical properties such as tensile strength, then sufficient tensile tests on the materials of interest, produced by the AMTs of interest, need be examined. The specific number of tests is determined by the statistics of the digital platform to achieve correlation, and to adequately span the possible range of potential build issues and to capture their effect on the properties of interest.

Both step 4 and step 5 are proposed as a potential replacement for the supplemental testing outlined as step 3 in Figure 9. It is expected that the first few component applications manufactured under this approach would still have supplemental testing requirements as outlined in the NRC's draft AMT guidelines. However, as experience is gained with using a digital platform and predicted component performance, approval could be requested to reduce and eventually eliminate the need for supplemental testing after sufficient successful applications. However, it is too early to know for certain what decrease in supplemental testing requirements there would be without additional examples and trial-use applications. It is also unclear if this 
approach offers consistent value for every AMT, material, and nuclear application of interest. These steps are meant to present at a high-level, a potential alternative to component level benchmarking, with the exact value and best use cases to be determined later by additional examples and trial applications.

- Step 6, production process control and verification, is essentially the same as that documented in the NRC's draft AMT guidelines but with additional emphasis on the data required by the digital platform to also be controlled and verified. Witness sample collection and testing is not anticipated to be different when the digital platform is used to inform component certification. However, like supplemental testing, any component level product verification that requires a significant number of additional builds or destructive evaluations, would ideally be reduced, and replaced with digital platform-based component performance predictions. It should be noted that this could also include engineering analysis simulations or other modeling to demonstrate quality in conjunction with the digital platform's informed predictions for material property and component performance.

- Step 7, performance monitoring, is also very similar to the performance monitoring step in the NRC's draft AMT guidelines. Inspection, again management, and post-service evaluation are critically important. However, an additional element is added for feedback into the digital platform to potentially improve future designs, while remaining within the application envelope.

The proposed approach and the elements within each step are described in Table 1 through Table 7. These elements are not intended to be fully encompassing of all the effort required to meet the stated goal, but rather provide a starting point for program interested in adopting a digital platform-informed certification approach. As experience and program maturity is gained with the digital platform, additional elements and action items will become apparent.

Table 1 describes Step 1, program competency and quality assurance, in more detail. 
Table 1. Step 1. Program Competency and Quality Assurance

\begin{tabular}{|c|c|}
\hline \multirow{2}{*}{$\begin{array}{l}\text { Goal: } \\
\text { Elements }\end{array}$} & $\begin{array}{l}\text { program capability and desired outcomes for AMT-derived components to be } \\
\text { ations informed by a digital platform }\end{array}$ \\
\hline & \multirow[b]{2}{*}{$\begin{array}{l}\text { Description and Action Items } \\
\text { - } \quad \text { Develop and implement a robust nuclear QA program and procedures around AM } \\
\text { processes } \\
\text { Qualify special processes and systems under internal QA program and utilizing } \\
\text { commercial grade dedication where necessary including powder acquisition/use, } \\
\text { AM machines, Characterization systems, Video, Post-treatment, Post-processing, } \\
\text { and final Inspection. } \\
\text { - Train and qualify personnel to perform their roles and functions } \\
\text { - Apply nuclear Software Quality Assurance to software items used for } \\
\text { manufacturing components with a safety application } \\
\text { - Adopt national AM and other applicable nuclear and non-nuclear codes \& } \\
\text { standards } \\
\text { Develop process to inform final certification with inspection, testing and digital } \\
\text { platform inputs }\end{array}$} \\
\hline 1.1 QA program & \\
\hline $\begin{array}{l}\text { IT infrastructure } \\
\text { and data } \\
\text { management } \\
\text { plan }\end{array}$ & $\begin{array}{l}\text { - Either as part of the QA program or separate, an IT infrastructure and data } \\
\text { management is necessary to ensure build data is recorded and stored properly. It is } \\
\text { also necessary to ensure all physical testing and ex-situ data is recorded and stored } \\
\text { properly } \\
\text { - Include specifications on how the digital platform is to be installed and maintained } \\
\text { - Include security and access control measures to ensure data integrity and for any } \\
\text { export control or sensitivity material }\end{array}$ \\
\hline $\begin{array}{l}\text { Define program } \\
\text { goals }\end{array}$ & $\begin{array}{l}\text { - Construct a document or other tangible object that sets the high-level goals for } \\
\text { nuclear applications within the advanced manufacturing program (e.g., "To 3-D } \\
\text { print nuclear fuel and reactor components to be used in the New Reactor concept") } \\
\text { - This document or other object is necessary to generate and flow requirements to } \\
\text { the specific applications of interest }\end{array}$ \\
\hline
\end{tabular}

It is recognized that the elements contained within step 1 would likely be completed well before the first AMT-derived component is manufactured. In many cases, companies and organizations supporting nuclear technology development have been in business before 3-D printing was made broadly available and have already demonstrated the step 1 elements. However, for new reactor concepts and start-up companies entering the nuclear technology development business environment for the first time, the step 1 elements are strongly encouraged before proceeding to later steps. Table 2 describes the critical elements for developing an application requirements envelope. 
Table 2. Step 2. Application Requirements Envelope

\begin{tabular}{|c|c|c|}
\hline \multicolumn{2}{|c|}{ Goal: } & \multirow{2}{*}{$\begin{array}{l}\text { equired properties and tolerances for the desired applications } \\
\text { Description and Action Items }\end{array}$} \\
\hline & ients & \\
\hline & $\begin{array}{l}\text { System, component, } \\
\text { and part design } \\
\text { requirements }\end{array}$ & $\begin{array}{l}\text { - Identify the types and range of parts and components to be manufactured by } \\
\text { the AMTs for which the digital platform is to be used to inform their } \\
\text { certification } \\
\text { For each part or component, document the design requirements, materials, } \\
\text { functions, reliability objectives, and its importance to safety and/or safety } \\
\text { design requirements }\end{array}$ \\
\hline & $\begin{array}{l}\text { Identify AMTs and } \\
\text { materials }\end{array}$ & $\begin{array}{l}\text { - For each part or component, identify the AMTs used for manufacturing } \\
\text { - Identify the feedstock materials } \\
\text { - Identify post-processing, machining, or other steps necessary to construct the } \\
\text { part or component }\end{array}$ \\
\hline & $\begin{array}{l}\text { Identify the critical } \\
\text { AMT parameters }\end{array}$ & $\begin{array}{l}\text { Identify the critical parameters associated with the desired AMTs (e.g., } \\
\text { minimum layer thickness, scan strategy) }\end{array}$ \\
\hline & $\begin{array}{l}\text { Identify the critical } \\
\text { physical properties } \\
\text { and parameters }\end{array}$ & $\begin{array}{l}\text { - For the desired applications, identify the critical physical properties and } \\
\text { parameters which impact the part or component's performance (e.g., tensile } \\
\text { strength) }\end{array}$ \\
\hline
\end{tabular}

For some material, AMT of interest, the application requirements envelop sets the requirements for which the digital platform needs to collect both the in-situ and ex-situ data. Figure 15 illustrates what the application requirements envelope is and how it subsumes all the requirements of the desired components to be manufactured through this approach.

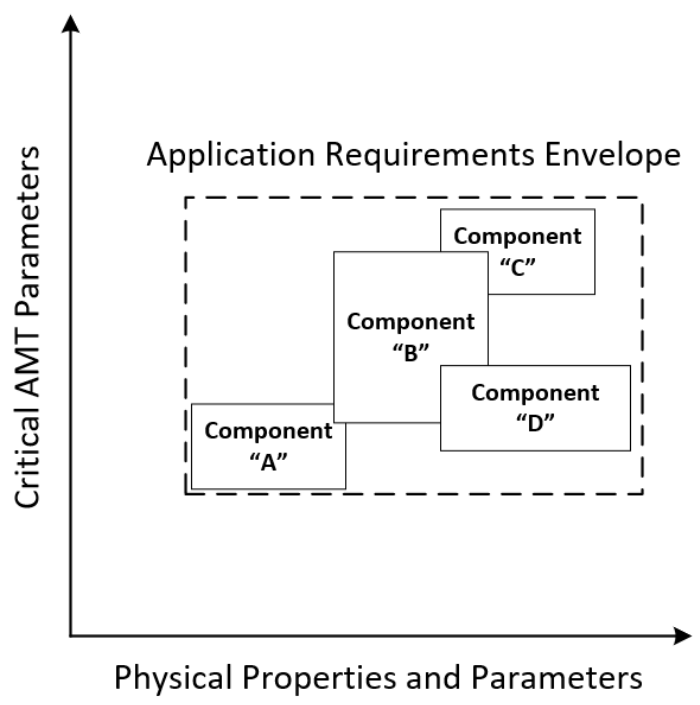

Figure 15. Application Requirements Envelope

The hypothesis is that the cost of certifying the application requirements envelope, the dashed line in Figure 15 is less than cost of certifying each individual AMT-derived component. Then, it becomes more cost effective as the number of applications increase without expanding the box or envelope which would necessitate further testing and digital platform capabilities. 
Both step 1 and step 2 are performed with every desired application in consideration. The following steps are performed for each application. However, the degree for which they are performed may be slightly different depending on the application and order in the manufacturing process. Depending on the safety significance of each component and any special requirements, Step 3 could have significant overlap between different AMT-derived components. However, it is proposed here for each component as the application and safety significance of each produced could be sufficiently different to perform these different documentation steps.

Similar with step 4, digital platform, many of the proposed elements will be the same as or use the same approach for every component produced. The proposed elements within these steps are not intended to be fully encompassing, but rather, to initiate the discussion and examine the high-level aspects for developing a more comprehensive process in the future.

Table 3. Step 3. Process Qualification

\begin{tabular}{|c|c|c|}
\hline \multirow{2}{*}{\multicolumn{2}{|c|}{$\begin{array}{l}\text { Goal: } \\
\text { Elements }\end{array}$}} & \multirow{3}{*}{$\begin{array}{l}\text { I define how the desired components are manufactured, what defects are } \\
\text { defects are measured, and industrial codes and standards } \\
\begin{array}{l}\text { Description and Action Items } \\
\text { - Identify all relevant industrial codes and standards to be followed for the } \\
\text { specific AMT and materials of interest }\end{array}\end{array}$} \\
\hline & & \\
\hline & $\begin{array}{l}\text { Industrial codes and } \\
\text { standards }\end{array}$ & \\
\hline 3.2 & $\begin{array}{l}\text { Process } \\
\text { qualification testing }\end{array}$ & $\begin{array}{l}\text { - Perform and document all initial testing and startup procedures in accordance } \\
\text { with the manufacturer guidelines } \\
\text { - Manufacture and test any articles (generally at ambient air conditions) to } \\
\text { ensure the desired components will meet all necessary and application codes } \\
\text { and standards } \\
\text { - Identify the characterization methods and techniques } \\
\text { - Identify and document any potential defects }\end{array}$ \\
\hline 3.3 & $\begin{array}{l}\text { Heat treatment and } \\
\text { other post- } \\
\text { operations }\end{array}$ & $\begin{array}{l}\text { - Identify the required post operations such as heat treatment, polishing, or } \\
\text { electric discharge machining } \\
\text { - Demonstrate these satisfy the application requirements and that significant } \\
\text { defects are not introduced }\end{array}$ \\
\hline & $\begin{array}{l}\text { Understanding of } \\
\text { defects }\end{array}$ & $\begin{array}{l}\text { - For the specific AMT and materials of interest, document the relationship of } \\
\text { potential defects to part/component quality } \\
\text { - Ensure the bounds of the critical AMT parameters are chosen such that } \\
\text { significant defects are not introduced }\end{array}$ \\
\hline
\end{tabular}


Table 4. Step 4. Digital Platform

\begin{tabular}{|c|c|}
\hline $\begin{array}{l}\text { Demonstrate } \\
\text { necessary to c }\end{array}$ & $\begin{array}{l}\text { t data is secure, accessible, easily understood, and contains the AI/ML tools } \\
\text { relate ex-situ and in-situ data, and to predict component performance }\end{array}$ \\
\hline Elements & Description and Action Items \\
\hline 4.1 Data collection & $\begin{array}{l}\text { - Store all relevant manufacturing, in-situ, and ex-situ data in a system suitable } \\
\text { for both human accessibility and AI/ML correlation } \\
\text { - Ensure all identified critical AMT process parameters are collected and stored } \\
\text { in the digital platform for each component to be manufactured within the } \\
\text { application requirements envelope } \\
\text { - Provide a system for inspecting and analyzing the manufacturing and in-situ } \\
\text { data during or just after manufacturing }\end{array}$ \\
\hline 4.2 Data integrity & $\begin{array}{l}\text { - Maintain procedures and access control for all data relevant to the } \\
\text { manufacturing of components and to the correlation of ex-situ and in-situ data } \\
\text { - Maintain sufficient cybersecurity to ensure data integrity } \\
\text { - Ensure that data has the proper identification to be easily traceable and } \\
\text { accessible }\end{array}$ \\
\hline $4.3 \quad$ Digital thread & $\begin{array}{l}\text { Develop the system (databases, etc.) to properly track a part/component for all } \\
\text { life-cycle phases, from conceptualization to decommissioning } \\
\text { - Ensure this system has sufficient capability to store or link/connect with all } \\
\text { pertinent design and engineering analyses, calculation files, reports, modeling } \\
\text { files, etc., which may be required of the regulator, or for future design } \\
\text { improvement gained from operational feedback }\end{array}$ \\
\hline 4.4 AI/ML correlations & $\begin{array}{l}\text { - Identify/select appropriate } \mathrm{AI} / \mathrm{ML} \text { algorithms } \\
\text { - Verify, if necessary, outputs or other data produced by the selected } \mathrm{AI} / \mathrm{ML} \\
\text { algorithms } \\
\text { - Employ/train AI/ML to correlate in-situ observations with ex-situ performance } \\
\text { values }\end{array}$ \\
\hline
\end{tabular}

The type and quantity of physical testing needed to support the correlations of the digital platform depends on the physical properties and parameters of those components contained in the application requirements envelope. As such, it is impractical to list specific elements related to the multitude of different testing which may be required to train or learn any possible correlation with in-situ data. Therefore, only a few high-level elements are proposed and are provided in Table 5. 
Table 5. Step 5. Ex-situ (Physical) Data Collection

\begin{tabular}{|c|c|c|}
\hline \multirow{2}{*}{\multicolumn{2}{|c|}{$\begin{array}{l}\text { Goal: } \quad \text { co } \\
\text { Elements } \\
\text { co }\end{array}$}} & \multirow[b]{3}{*}{$\begin{array}{l}\text { Description and Action Items } \\
\text { - From the components identified in the application requirements envelope, } \\
\text { develop a test campaign centered around performing physical material property } \\
\text { tests using AMT-derived test elements } \\
\text { The objective of these tests is to provide the physical properties for AMT- } \\
\text { derived test elements which span all critical AMT parameters that may be } \\
\text { expected to produce an acceptable component } \\
\text { It may be practical to divide the test campaign into phases depending on } \\
\text { several factors including those: (a) different test elements produced with } \\
\text { different critical AMT parameter values, (b) different AMT machines or } \\
\text { manufacturing processes, (c) different materials, (d) different physical test } \\
\text { element designs or those requiring a different testing approach, (e) } \\
\text { cost/efficiency/or other programmatic factors } \\
\text { All physical testing should conform with specified QA standards and best } \\
\text { practices appropriate for the desired component applications }\end{array}$} \\
\hline & & \\
\hline & $\begin{array}{l}\text { Test campaign } \\
\text { development }\end{array}$ & \\
\hline & $\begin{array}{l}\text { Physical test } \\
\text { elements }\end{array}$ & $\begin{array}{l}\text { - Determine a bounding (approximate) number of physical test elements needed } \\
\text { to span all critical AMT parameters that may be expected to produce an } \\
\text { acceptable component and construct a strong correlation with the in-situ data } \\
\text { Design the physical test elements according to their test parameters, and such } \\
\text { that their component volume, mass, manufacturability is optimized to yield a } \\
\text { bounding number of elements } \\
\text { - If practical, minimize re-design, and the convolution of multiple critical AMT } \\
\text { parameters to simplify and better train the AI/ML to correlate with their impact } \\
\text { on physical properties and parameters }\end{array}$ \\
\hline & $\begin{array}{l}\text { Digital platform } \\
\text { integration }\end{array}$ & $\begin{array}{l}\text { Evaluate correlated ex-situ and in-situ data at appropriate intervals during the } \\
\text { test campaign } \\
\text { Determine if/where gaps exist and develop a plan to manufacture and test } \\
\text { additional elements if needed to better correlate ex-situ data with remaining or } \\
\text { bounding critical AMT parameter values }\end{array}$ \\
\hline
\end{tabular}

Once all necessary digital platform and material property correlation development has been completed, the application components (i.e., those to be certified through this digital platform-informed process) can then be manufactured. Table 6 highlights the elements proposed as part step 6, production process control and verification. Figure 16 shows a proposed process flow for determining the extent of verification testing based on the results of the manufacturing and experience and confidence in the digital platform. 
Table 6. Step 6. Production Process Control and Verification

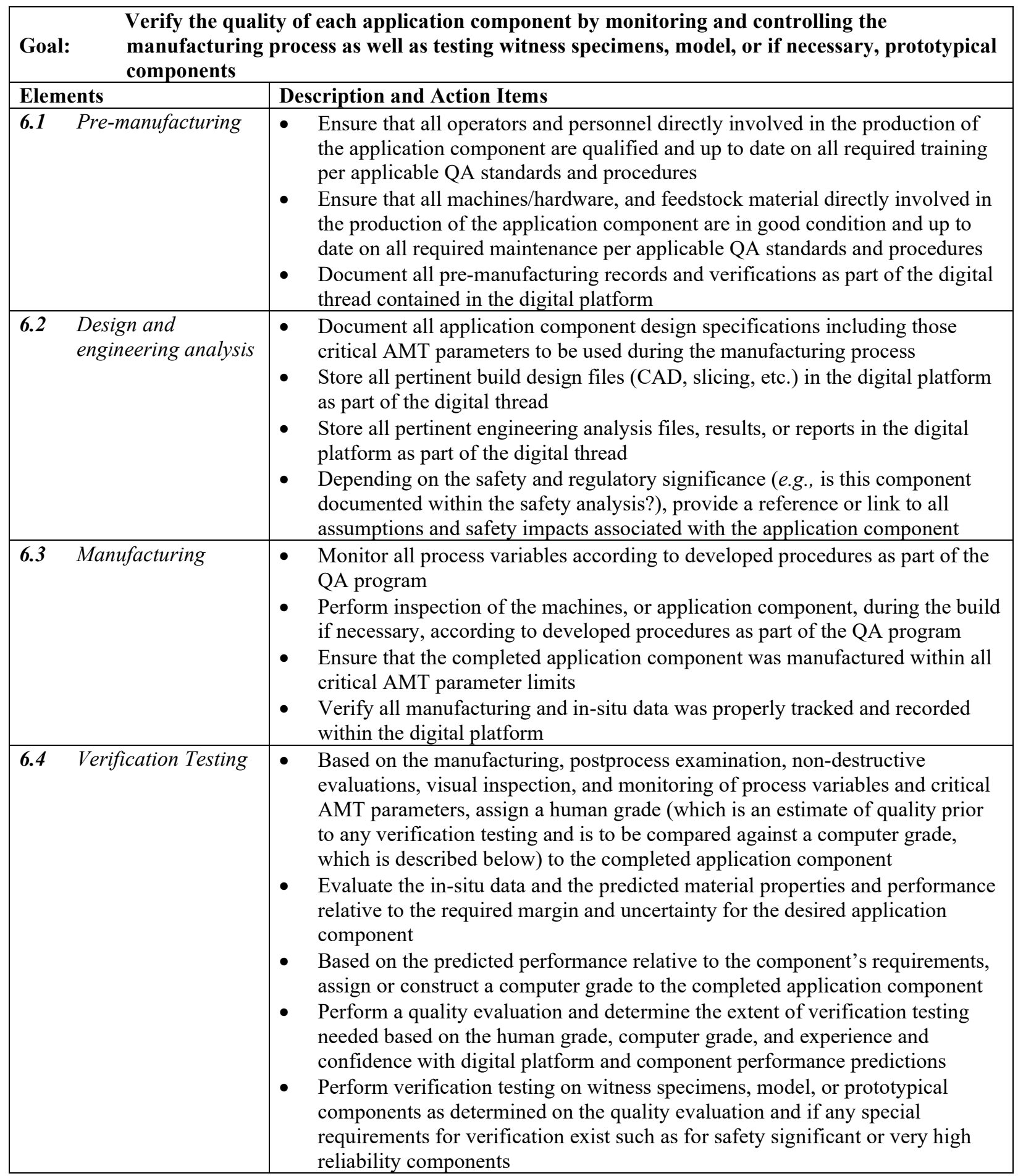




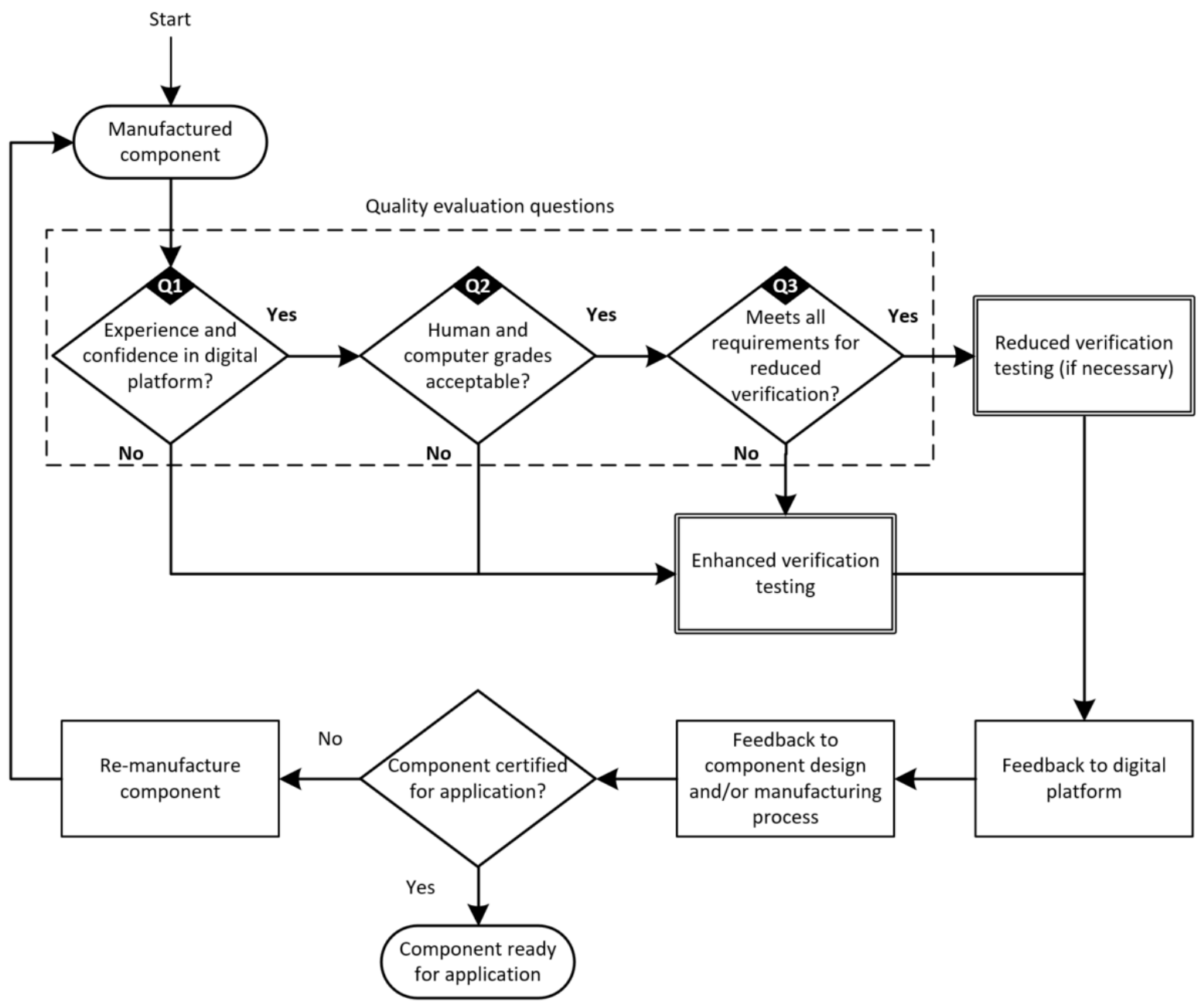

Figure 16. Proposed Verification Testing and Quality Evaluation Process Steps

In Figure 16, the quality evaluation questions should be asked as part of element 6.4, verification testing, for each component. The experience and confidence in the digital platform are increased after each verification test that demonstrates the digital platform's successful component performance prediction. For the first, or first few, components manufactured through this approach, the answer to Q1 is likely to be "No". For a general application, AMT, and component, it is difficult at this stage to define specific criteria for what experience and confidence in the digital platform is necessary to answer Q1 as "Yes". This is likely to be established through trail-and-error with example applications first executing this or a similarly proposed process. Q2, human and computer grades, refers to the human evaluated, traditional postprocess examinations and the digital platform's predicted component performances respectively. For Q3, this refers to any special requirements which may dictate a prototype component at realistic operating conditions be evaluated. These special requirements could be because of many factors such as:

- novel or new function that component is expected to perform with no traditionally manufactured reference component,

- safety significant component that requires a strict performance margin and a small uncertainty around its safety performance (i.e., fulfilment of a critical safety function), 
- to meet applicable code and standards requirements and does not have any approved relief from such requirements, and

- $\quad$ any other regulatory or programmatically imposed requirements.

As described earlier with the ex-situ physical testing step, the type and extent of verification testing is dependent on many factors. To determine what is enhanced, or what is reduced verification, the specific component, applicable industry codes and standards, regulatory, safety, and other requirements are necessary to evaluate. Therefore, these boxes are likely component-specific and may not be same for every component manufactured. However, if the answer to all three quality evaluation questions is "Yes", although the definition of reduced verification testing is the responsibility of the applicant of the proposed process, the intent is that this is less than or even eliminated completely from what may be traditionally performed for such a component or witness samples, based on those human and computer grades and the experience and confidence of such systems.

For verification testing steps, the results, either they demonstrate adequate component performance, or they do not, are included in the digital platform for future iterations of the same or similar components. These insights are also passed to the design and manufacturing teams to determine if the component is ready for application or if it should be re-manufactured. This evaluation, along with all necessary supporting documentation and QA demonstration sufficient for regulatory approval (depending on the specific application), would then lead to the component being certified for operation.

Once the component is in operation, step 7, performance monitoring is performed with the results being reported back to the appropriate design, digital platform, and regulatory teams. The proposed high-level elements of performance monitoring are described in Table 7. These elements are similar to those proposed in the draft NRC guidelines. However, an additional element is added for feedback and inclusion into the digital platform. 
Table 7. Step 7. Performance Monitoring

\begin{tabular}{|c|c|c|}
\hline \multirow{2}{*}{\multicolumn{2}{|c|}{$\begin{array}{l}\text { Goal: } \\
\text { Elements }\end{array}$}} & \multirow[b]{3}{*}{$\begin{array}{l}\text { Description and Action Items } \\
\text { - } \\
\text { Assess the areas most critical to component performance and where age-related } \\
\text { degradation could occur } \\
\text { - Determine how much age-related degradation is tolerable for successful } \\
\text { component application and function } \\
\text { - Assess whether feasible or necessary to modify inspection frequency or } \\
\text { develop an inspection strategy if it is a new reactor or application } \\
\text { - Determine the inspection approach } \\
\text { - Perform inspections per the applicable code and standard requirements or other } \\
\text { approved methodologies } \\
\text { - Document observations and any service-induced degradation that may lead to } \\
\text { unacceptable performance } \\
\text { Record inspection results of the component in the digital platform to maintain } \\
\text { the component's digital thread }\end{array}$} \\
\hline & & \\
\hline & Inspection & \\
\hline & Aging Management & $\begin{array}{l}\text { - Evaluate inspection data and determine if/when a loss of component } \\
\text { performance may be expected due to age-related degradation } \\
\text { - If a formal aging management plan is established, consult with, or determine } \\
\text { if/when the component should be replaced or performed maintenance on to } \\
\text { prevent a loss of component function due to age-related degradation } \\
\text { - Record all aging management and maintenance activities in the digital platform } \\
\text { to maintain the component's digital thread }\end{array}$ \\
\hline & $\begin{array}{l}\text { Postservice } \\
\text { Evaluations }\end{array}$ & $\begin{array}{l}\text { Determine the extent of postservice evaluations to perform based on the } \\
\text { component function and safety significance, existing postservice evaluation } \\
\text { data for it or similar components, the amount of age-related degradation, cost, } \\
\text { technical limitations (e.g., hazard/radioactivity levels), or other factors } \\
\text { - Perform postservice destructive and/or NDEs } \\
\text { - Record and store relevant postservice evaluation data in the digital platform to } \\
\text { maintain the component's digital thread }\end{array}$ \\
\hline & $\begin{array}{l}\text { Digital Platform } \\
\text { Integration and } \\
\text { Digital } \\
\text { Manufacturing } \\
\text { Feedback }\end{array}$ & $\begin{array}{l}\text { - Depending on the extent of age-related degradation and postservice } \\
\text { evaluations, re-evaluate any inspection, aging management, and postservice } \\
\text { evaluation data and to identify any manufacturing or material defects which } \\
\text { could correlate to age-related degradation beyond normal or expected service } \\
\text { behavior } \\
\text { - Consider the importance of these defects on age-related degradation for future } \\
\text { components manufactured through this proposed process } \\
\text { - Consider how might any age-related degradations beyond normal or expected } \\
\text { service behavior be mitigated by the AMT, material, or manufacturing process } \\
\text { - Consider if the digital platform, or engineering analysis capabilities, is } \\
\text { sufficient to predict or account for any age-related degradations beyond normal } \\
\text { or expected service behavior } \\
\text { - If any new critical defects are linked or correlated to age-related degradation, } \\
\text { perform a review or search through other AMT-derived components through } \\
\text { this proposed process that may be impacted by similar phenomena } \\
\text { - Incorporate any lessons learned into new components and document or add a } \\
\text { reference to the digital thread for existing components which may be impacted } \\
\text { by similar defects }\end{array}$ \\
\hline
\end{tabular}




\section{TCR APPLICATION EXAMPLE OF DIGITAL PLATFORM INFORMED CERTIFICATION}

This section describes an initial application example of the proposed digital platform-informed certification process. The goal of this example is to demonstrate component performance prediction using correlated in-situ and ex-situ data within the digital platform. To focus the testing scope on completing this goal, minimize complexity and any surrounding issues with manufacturing, materials, AI/ML, and test conditions, the application example is selected to be as simple as possible. To that end, the example AMT-derived component was selected to be short, small diameter, stainless steel tubes with no requirements other than to hold a certain pressure at an elevated temperature for a brief period. These are herein referred to as "burst tubes".

This application example is not intended to gain full confidence of the digital platform or such proposed approach, but rather, to demonstrate digital platform-based component predictions for an initial case. It is expected that many test cases will be needed to fully develop this confidence and to be able to expand it to a real application. Real applications are likely to have more desired functionality than the burst tubes described here. However, the simplicity of such application an example allows for a clear assessment and of the AIR's ability to predict the component's performance (i.e., what the maximum pressure, hoop stress before rupture is).

Elements of the proposed approach for the digital platform-informed certification process are described in this section as they relate to the application example. However, it should be mentioned that testing of the burst tubes are ongoing and complete results are not expected at time of writing of this report. Therefore, conclusions drawn about the digital platform for TCR, observed from these burst tube tests, are incomplete and will require a follow-on report.

\subsection{TCR INFRASTRUCTURE AND PROGRAM GOALS}

The first step in the proposed approach is to demonstrate program capability and articulate the desired outcomes for AMT-derived components to be their certifications informed by a digital platform. For TCR, and likely other programs which would follow this proposed approach, this objective is met across several supporting documents and the facilities and hardware referenced by such. This section briefly describes these program supporting documents.

Activities associated with DOE nuclear facilities are governed by 10 CFR 830, Subpart A, "Quality Assurance Requirements" and DOE Order 414.1D, "Quality Assurance." To meet these requirements, ORNL implements a QA Program Description (QAPD), which serves as the highest tier QA document for the site. The ORNL QAPD is an umbrella document for the TCR QA Program. The ORNL QAPD has been approved by the DOE. 10 CFR 830 requires all contractors conducting activities that affect nuclear safety develop a Quality Assurance Program (QAP) which addresses the elements of 10 CFR 830.122, Quality assurance criteria, and submit to DOE for approval. Since this has been done for the ORNL QAPD no additional DOE approval is required for TCR QA program documents (the TCR QAP).

A central aspect of the TCR program is the digital framework and associated data generated as part of the program. Consequently, a data management plan has been developed and implemented to develop, store, secure, access, transfer, maintain, share, and preserve electronic and physical data for the TCR Program [34]. This plan applies to electronic and hardcopy data developed in support of the TCR program, including scientific research, engineering, safety analysis, simulation, design, manufacturing, characterization, calculations, irradiation/testing, handbooks, lab notebooks, and related information.

A major component of ORNL's advanced manufacturing capabilities at ORNL is the Manufacturing Demonstration Facility, a 110,000 sq. ft. facility housing integrated capabilities that drive the development of new materials, software, and systems for advanced manufacturing. Research focuses on 
manufacturing analysis and simulation, composites and polymer systems, metal powder systems, metrology and characterization, machine tooling, large-scale metal systems, and robotics and automation. Advanced manufacturing technologies pertinent to nuclear applications leveraged at the MDF include Laser Powder Bed Fusion, Binder Jetting and Directed Energy Deposition. In general, the MDF leverages a range of equipment and expertise focused on reducing the carbon footprint of the manufacturing sector, efficiently utilizing abundant and available domestic energy resources, and supporting the production of clean energy products.

Program goals for the TCR have been captured in a Program Management Plan. The stated objective of the TCR program is to bring to bear additive manufacturing and AI to accelerate the deployment of enabling technologies for the advanced nuclear reactor industry. Demonstrations are pursued to enforce technical rigor, efficacy, and regulatory acceptance of newly developed technologies and processes. Procedures for manufacturing AM components for TCR are primarily documented in two reports:

- ORNL/TM-2020/1736, Quality Procedures for TCR Metal Core Structure Advanced Manufacturing Processes Report [35], and

- ORNL/TM-2021/1974, Compilation of Quality Procedures for Ceramics Advanced Manufacturing Processes [36].

Comments, questions, or concerns with any of the TCR program documents mentioned may be brought to the authors of this report or ORNL.

\subsection{APPLICATION REQUIREMENTS ENVELOPE}

As proposed in step 2, an application requirements envelope is necessary to support the certification of a multitude of AMT-derived components desired by the program. The application requirements envelope specifies the range of critical AMT parameters for which parts and components can be constructed by specified AMT processes and be validated to meet such requirements using both traditional and digital platform-informed certification approaches. Critical AMT parameters can include but are not limited to parameters such as: feedstock material, composition, and recycling schemes, maximum and minimum build volume, minimum wall thickness, maximum porosity, laser scan strategies, etc. Regardless of the AMT utilized, a well-defined application envelope includes design, materials, manufacturing, postprocessing, and acceptance is required.

For the application example described here, the requirements envelope is trivial as it encompasses just a single component. For future testing, this envelope may broaden as different components are proposed to be tested for demonstrating the AIR's prediction capabilities. The requirements for the burst tube are specified below in Table 8.

Table 8. Application Example Requirements

\begin{tabular}{|l|r|}
\hline Parameter & Value \\
\hline Material & AM SS316L \\
\hline Geometry & Cylindrical Tube \\
\hline AMT type & LPBF \\
\hline Number of tests/builds & $7.000 \quad$ in. \\
\hline Length & $0.625 \quad$ in. \\
\hline Outer diameter & $0.030 \quad$ in. \\
\hline Wall thickness & $13.8 \quad \mathrm{MPa}$ \\
\hline Critical test pressure & $\sim 850 \quad{ }^{\circ} \mathrm{C}$ \\
\hline Critical test temperature &
\end{tabular}


The parameters described in Table 8, were chosen to coordinate with an existing test facility at ORNL which could easily accommodate our schedule and objectives for the current year. Since the purpose of the burst tests is not related to the specific design parameters, these application example requirements were judged to be acceptable.

The critical pressure is the pressure of the gas which is to be contained within the tube for a brief period at an elevated temperature. The exact length of time is not specified but it is necessary for it to be short enough to not result in significant creep, which would lower the mechanical stress necessary for rupture. This is required because of the extensive database of tensile strength testing, for which the AI/ML is correlated with in-situ data, does not include creep rupture.

\subsection{PROCESS AND DIGITAL PLATFORM QUALIFICATIONS}

In terms of fulfilling the proposed process as illustrated in Figure 14, much of the process and digital platform qualification elements have been described in this report in section 2. In particular, the Concept Laser machines shown in Figure 6 were used for the manufacturing of these burst tubes. The referenced ORNL digital platform reports also describe many of the proposed elements for digital platform qualification. This information along with the described TCR program documents constitute the fulfilment of steps 3 and 4 as shown in Figure 14. As this digital platform-certification process evolves, and for future application example tests, a separate standalone report containing the basis and description of each certification element may be more useful.

\subsection{EX-SITU (PHYSICAL) DATA COLLECTION}

The purpose of this application example is to test what the burst pressure is and if the digital platform can predict the value. For a cylinder, the burst pressure, not under creep conditions, is related to UTS of the material. In FY20, 586 AM SS316L samples across three different LPBF builds were mechanically tested [37]. More samples are being tested in FY21 and FY22. The results from these tests and their in-situ data constitute the necessary information required by the AI algorithms within the digital platform to learn relevant correlations. The samples are standard SS-J3 tensile bars (Figure 17).

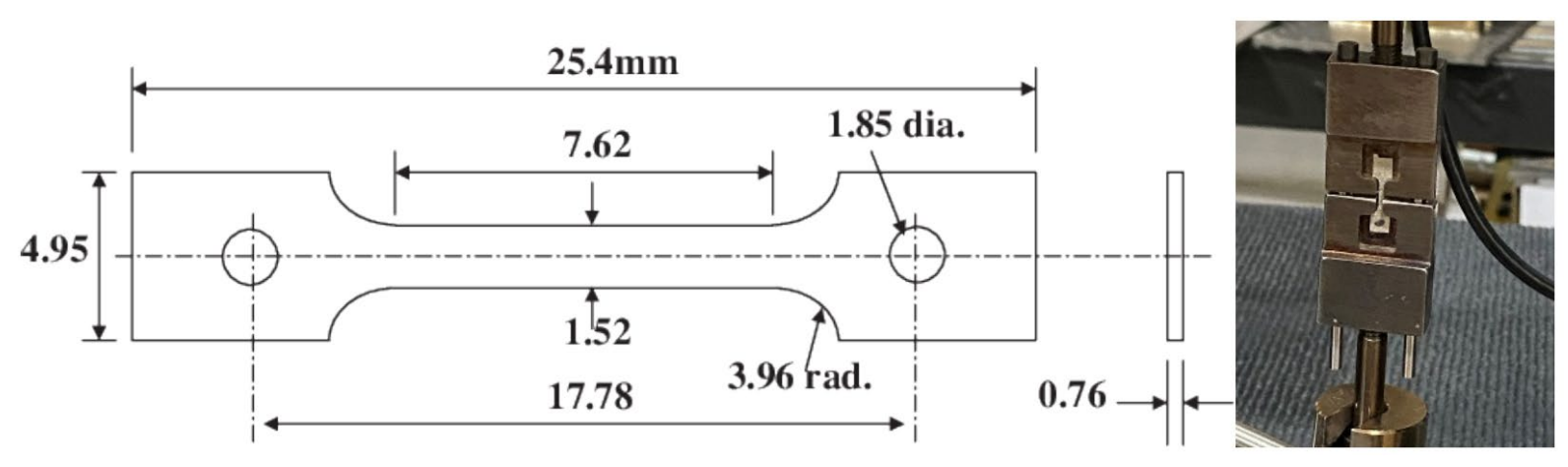

Figure 17. Standard SS-J3 Mechanical Testing Specimen (Left) and the Testing Apparatus (Right) [34]

For reference, the mean UTS derived from 353 tensile samples is $553 \mathrm{MPa}$ with a variance of 52.8. For a thin-walled pressure vessel, the hoop stress is given by (1):

$$
\sigma_{\theta}=\frac{P \bar{d}}{2 t}
$$


where, $P$ is the internal pressure, $\bar{d}$ is the mean diameter (diameter - thickness), and $t$ is the wall thickness. From this and the bust tube design dimensions in Table 8, to achieve a hoop stress of $553 \mathrm{MPa}$, the internal pressure would need to be around $46 \mathrm{MPa}$. This is unrealistic for the facility performing the burst tube experiments. Therefore, an elevated temperature is needed to reduce the UTS to realistic supplied internal pressure conditions. At an internal pressure of $13.8 \mathrm{MPa}$, which is attainable by the test facility, the applied hoop stress is approximately $165 \mathrm{MPa}$.

Since the mechanical testing of the tensile samples used to correlate the in-situ and ex-situ data in the digital platform was performed at room temperature, this then represents an assumption within the component prediction model to estimate what the burst pressure is at an elevated temperature.

\subsection{PRODUCTION AND VERIFICATION TESTING}

Approximately 50 burst tubes are currently under production and being tested in the Severe Accident Test Station at ORNL [38]. Results from the burst tube tests are expected soon and will be documented in a follow-on report. Similarly, the digital platform predicted UTS for the burst tubes, which can then be used to estimate the predicted burst pressure, will also be contained in the follow-on report. The burst tubes are manufactured across five builds. Burst tubes, as well as witness specimens and additional SS-J3 bars, are shown in Figure 18.
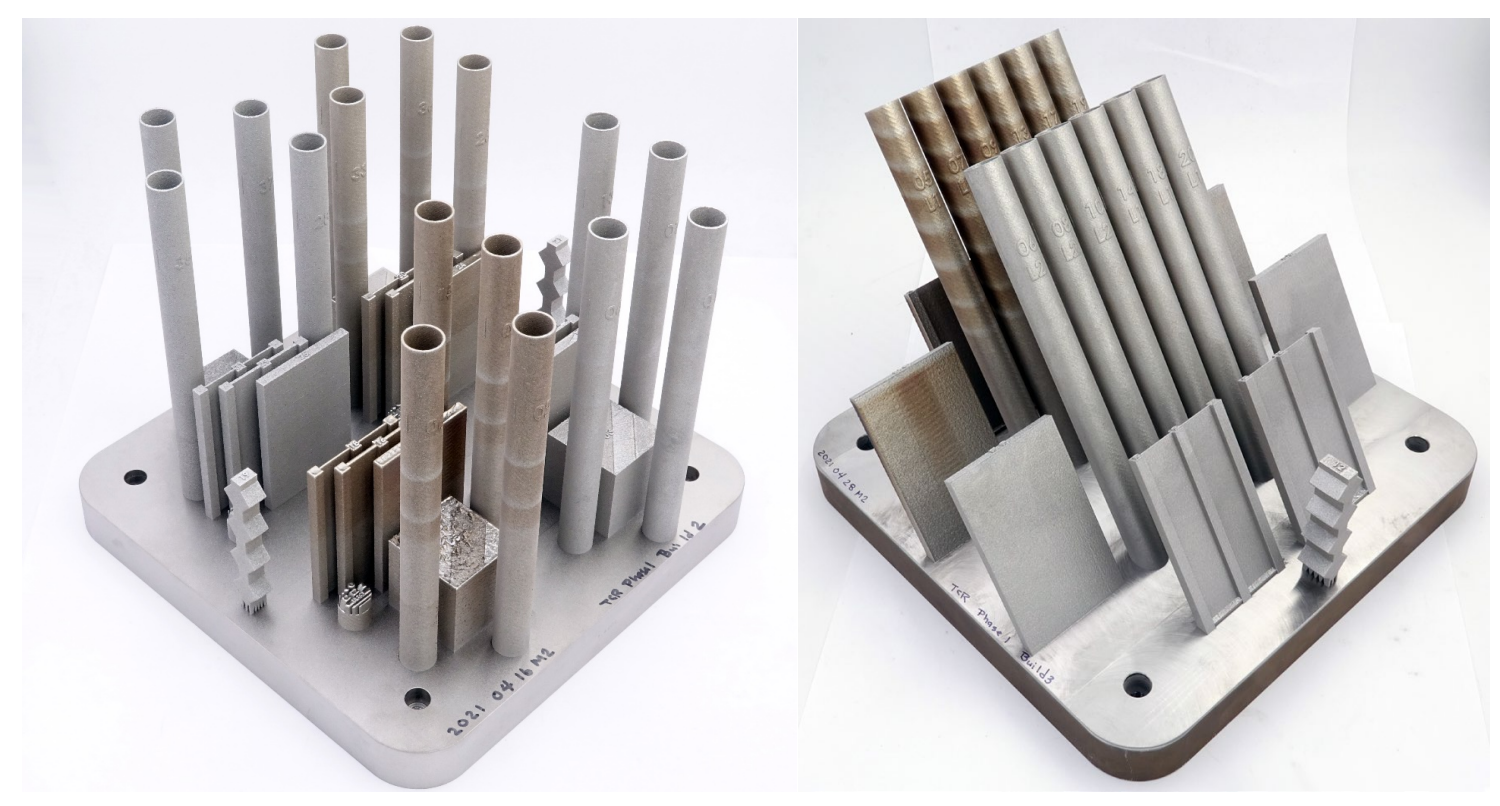

Figure 18. TCR Burst Tubes, Build 2 (Left), Build 3 (Right)

Burst testing, Figure 19 (a), is traditionally conducted on $\sim 305 \mathrm{~cm}$ lengths of internally pressurized cladding in a steam environment, and is typically performed as a highly relevant test simulating loss-ofcoolant accident conditions in light water reactors. Presently, several modifications to the test were implemented. The thin-walled cladding containing an alumina filler rod, Figure 19 (b), is internally pressurized to an initial nominal overpressure, where compression fittings at each end are used to hold pressure. The cladding train assembly is housed within a quartz reaction tube with flowing Ar, which in turn resides in a vertical IR furnace. Due to the shorter lengths, thick-walled 316SS extensions are used to 
center the cladding in the furnace hot zone. Internal pressure is continuously monitored with a transducer located outside the furnace. Four thermocouples are secured to the cladding with Type-B thermocouple wire, where one thermocouple placed at the claddings axial center is used to control the pre-programmed heating regime. A pressure and temperature profile during burst testing is shown in Figure 20. The cladding is internally pressurized and then taken through a series of isothermal holds, and ultimately to a $10^{\circ} \mathrm{C} / \mathrm{s}$ temperature ramp from $300^{\circ}$ to $1200^{\circ} \mathrm{C}$, during which cladding burst occurs. Burst is marked by a sudden decrease in pressure, where the furnace power is immediately cut-off once burst occurs. The temperature at burst is taken as the burst temperature, and the internal overpressure immediately prior to burst is taken as burst pressure. Burst hoop stress (Eq .1) is then calculated based off cladding geometry.
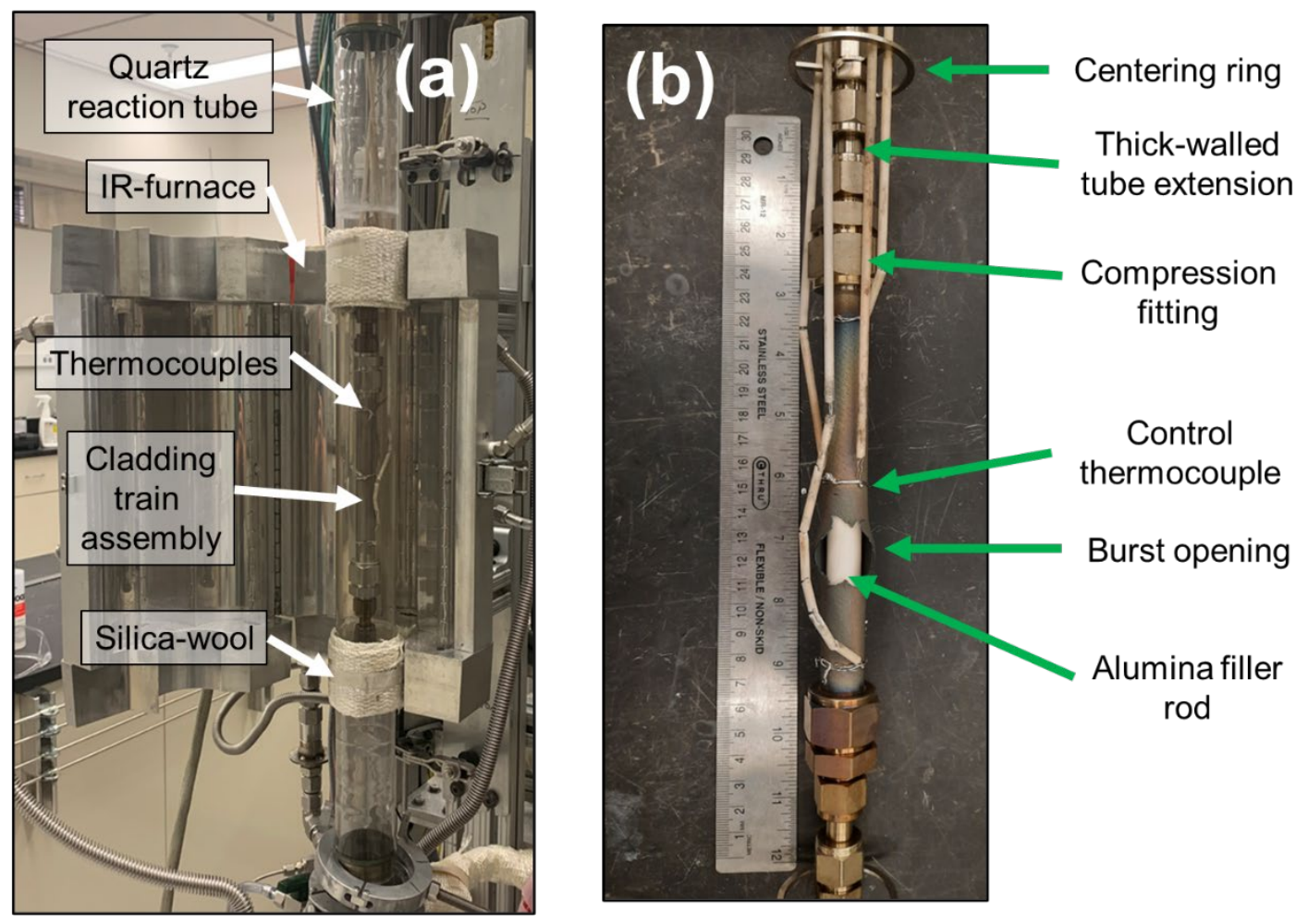

Figure 19. (a) Burst Testing Configuration and (b) Cladding Train Assembly Prior to Burst Testing. 


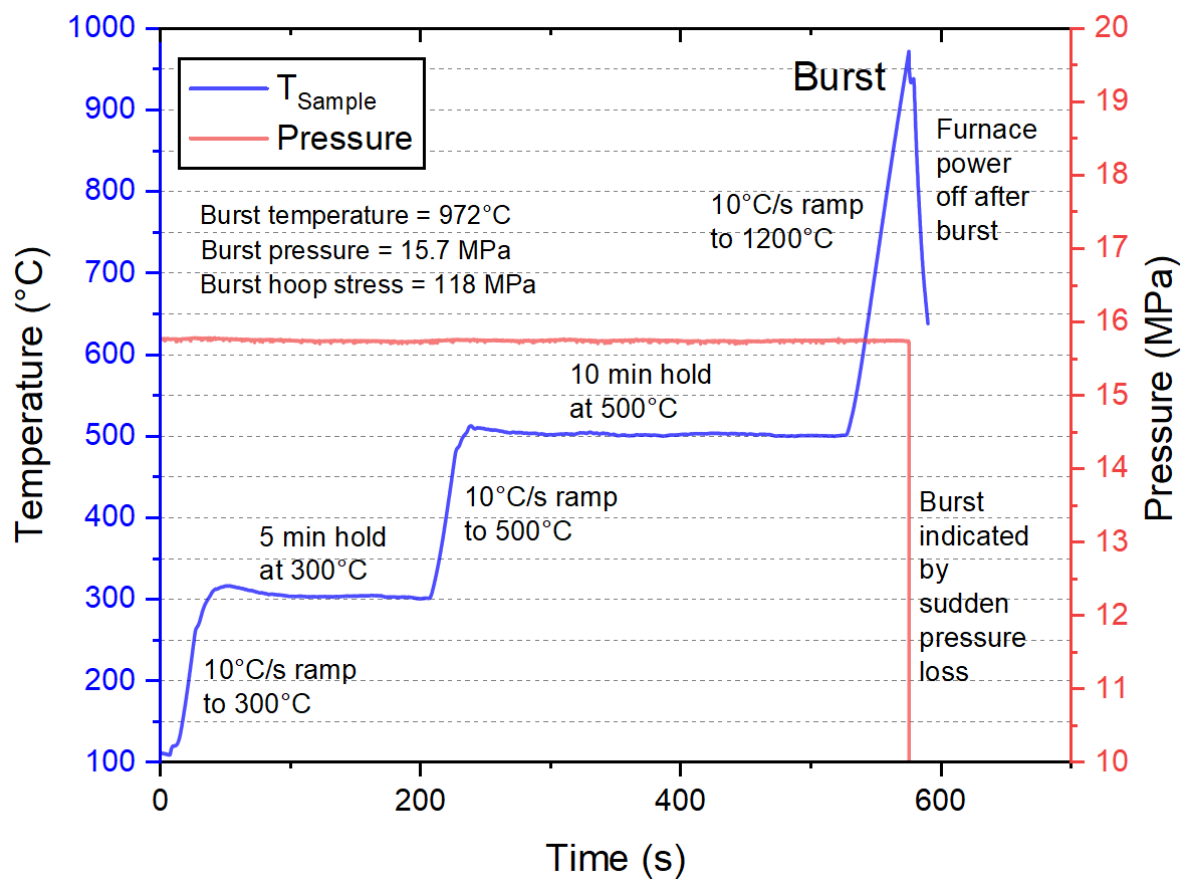

Figure 20. Pressure and Temperature Profile During Present Burst Testing, with Primary Segments Labeled

Preliminary burst testing was conducted on tubes from two different build, and the resultant burst stresses and burst temperatures are reported in Figure 21. Testing is still on-going, and analysis of burst stress is currently being conducted.

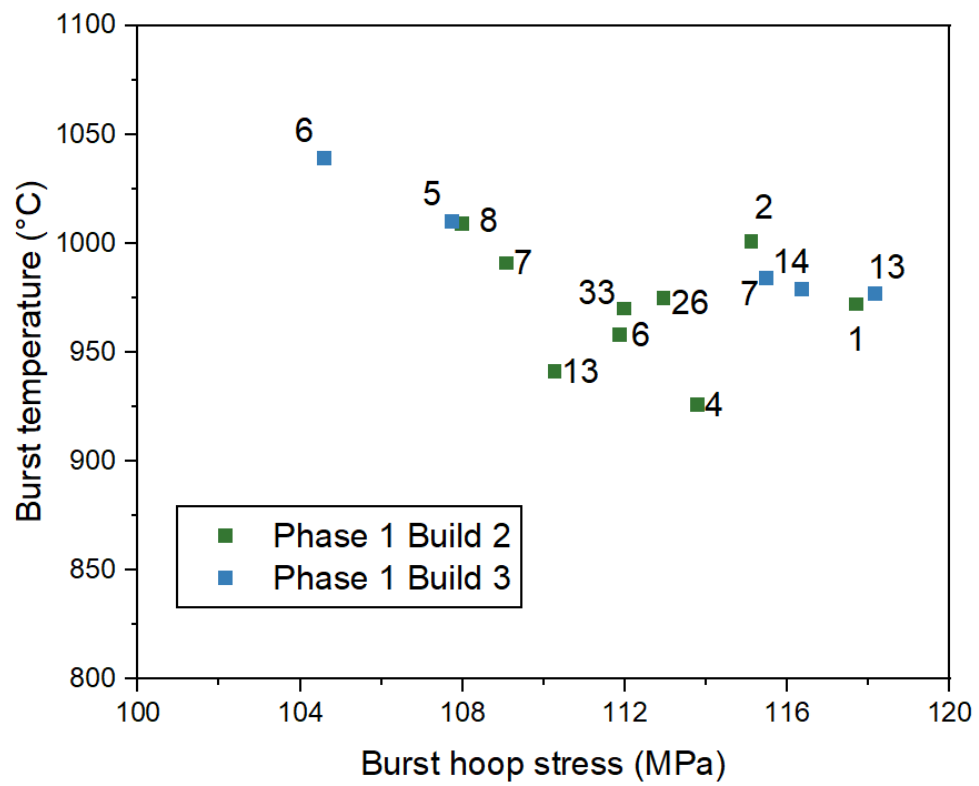

Figure 21. Relationship Between Burst Hoop Stress and Burst Temperature for Additively Manufactured Stainless Steel Tubing 


\subsection{DISCUSSION}

Although the testing of this application example is still ongoing, the TCR program has demonstrated that the infrastructure, data, manufacturing, and testing capabilities, can be stood up in a timely manner with modest budgets to support a digital platform-informed certification approach for some potential nuclear applications. However, pending the results of this application example and possible future tests, it remains to be seen if more complex example applications and those components with broader functionality, and/or different AMT types (such as DED or Binder Jet) can be certified using this approach.

Although the original intent was to have all testing and digital platform results by the time of writing this report, hardware/mechanical, and repair personnel availability and technical delays associated with the on-going worldwide pandemic contributed to the delay in the manufacturing and testing of the burst tubes. This is brought up only to emphasize to those nuclear developers considering the expanded use of components derived from AMTs, the importance of setting realistic program goals, which is an element of step 1 in the proposed certification approach, and to have proper risk mitigation and contingency plans. Despite these difficulties, considerable progress has been made and initial results are encouraging.

The next steps, in terms of accomplishing the stated goal of demonstrating component performance prediction using correlated in-situ and ex-situ data within the digital platform, is to:

1. complete the manufacturing and burst tube testing for the remaining tubes,

2. compare and evaluate the verification test data with those predicted values by the digital platform, and to

3. verify the performance of the AIR's correlation of ex-situ and in-situ data for this application example.

Insights are expected for any result from the burst tube tests. For the case where the AIR under-predicts the burst pressure, this demonstrates margin, but not because of any engineering safety factor, but rather, because there is an underlying data cause or issue with the approximation of using room temperature UTS as a starting point for extrapolating to a higher temperature value. Similarly, for the case where the AIR over-predicts burst pressure, this demonstrates the need for an additional engineering safety factor, which if too conservative, may negate some benefit of AM versus traditionally manufacturing and qualifying the component. For any outcome, including the case where the AIR nearly predicts the burst pressure, an investigation will be performed to gain a deeper understanding of what unit or voxel within in-situ data is driving a particular result. Additionally, there could be large uncertainties associated with the verification testing that may perhaps remove any fault or ownership of a potential cause from the digital platform. Even more consequential, could be an issue with the underlying ex-situ and in-situ data used to the train the AI algorithms in the digital platform.

The best case that supports the goal of demonstrating component prediction capability within the digital platform is one where the AIR's predictions match the burst tube validation test results, there are minimal uncertainties with these burst tube validation tests, and there is a high confidence in the underlying data and AI approach. This is expected; however, a follow-on report should be constructed to document this or any other result from these tests. 


\section{CONCLUSIONS}

A proposed digital platform-informed certification approach for AMT-derived components was presented. A simple application example test case of this proposed process was also presented. Although the results and confirmation of the digital platform's ability to predict component performance is still ongoing, the TCR program has shown some potential feasibility of the proposed approach in a short time frame and modest budget. One of the key advantages of such an approach is the reduction or elimination of costly supplemental and verification testing for a multitude of AMT-derived components. The central hypothesis of this approach is that it is cheaper and faster/more efficient to certify an application requirements envelope consisting of a set of potential AMT-derived components rather than certify each application individually. This scales as more AMT-derived components are to be manufactured that "fit" within the certified envelope.

There are many potential drawbacks to this proposed approach, some of which include:

- limiting envelope boundaries may constrain otherwise successful and novel application designs,

- it is unclear what number of desired applications is necessary to realize the benefit of certifying the envelope, rather than each application individually,

- real examples may be much more complex, and a significant gap remains between the burst tubes described in this report, and those employed in physical nuclear applications,

- the burst tubes requirements only have UTS as the critical physical parameter, which is also unrealistic for most real example applications,

- the number of physical tests required to train the AI for a robust correlation to in-situ data is already quite high for a single physical parameter. It is unclear if the required number of tests for additional physical parameters would grow exponentially or would be possible given modest and realistic program budgets and goals, and,

- regulatory uncertainty with AI and the ability to certify such a proposed process, versus using a more accepted, traditional approach by certifying individual AMT applications.

All the above points can be reduced or mitigated with additional testing and exploration of the proposed process and digital platform technology. One takeaway from the background, section 2, of this report, is that digital and advanced manufacturing has already disrupted several industries, such as the medical, aerospace, and defense industries. The nuclear industry needs transformative, cost reducing change, to stay competitive with other energy sources and to reduce global carbon emissions. In short, the nuclear industry is ripe for the expanded use of advanced manufacturing technologies, and a digital platform informed certification process has the potential to certify the greatest number of AMT-derived components while reducing the burden of supplemental and verification testing that may substantially slow their rate of adoption. 


\section{REFERENCES}

[1] OAK RIDGE NATIONAL LABORATORY, “Additively Manufactured Components by ORNL headed for TVA Nuclear Reactor," Press Release, Dated: October $19^{\text {th }}, 2020$. (October 2020) https://www.ornl.gov/news/additively-manufactured-components-ornl-headed-tva-nuclear-reactor

[2] NUCLEAR REGULATORY COMMISSION, “Implementation of Quality Assurance Criteria and 10 CFR 50.59 for Nuclear Power Plant Components Produced Using Advanced Manufacturing Technologies," ADAMS Accession No. ML21155A043, (July 2021).

[3] B. R. BETZLER et al., “Advanced Manufacturing for Nuclear Core Design,” Oak Ridge National Laboratory, ORNL/TM-2019/1258, (August 2019).

[4] U.S. NUCLEAR REGULATORY COMMISSION, “Advanced Manufacturing Technologies Application Guidance Framework,” ADAMS Accession Number: ML20203M254, (July 2020).

[5] U.S. NUCLEAR REGULATORY COMMISSION, "Draft Advanced Manufacturing Technologies Review Guidelines,” ADAMS Accession Number: ML21074A037, (July 2021).

[6] J. SIMPSON and R. DEHOFF, "Review of Advanced Manufacturing Techniques and Qualification Processes for Light Water Reactors-Laser Powder Bed Fusion Additive Manufacturing," ORNL/NRCHQ2514D000, (2020).

[7] U.S. NUCLEAR REGULATORY COMMISSION, "NRC Technical Assessment of Additive Manufacturing - Laser Powder Bed Fusion,” ADAMS Accession Number: ML20351A204, (January 2021).

[8] U.S. NUCLEAR REGULATORY COMMISSION, "Draft Guidelines Document for Additive Manufacturing - Laser Powder Bed Fusion," ADAMS Accession Number: ML21074A040, (July 2021).

[9] NUCLEAR ENERGY INSTITUTE, "Roadmap for Regulatory Acceptance of Advanced Manufacturing Methods in the Nuclear Energy Industry," (May 2019).

[10] GE ADDITIVE, “Metals in Additive Manufacturing \& 3D Printing," Website Accessed: August $1^{\text {st }}, 2021$. (August 2021).

https://www.ge.com/additive/additive-manufacturing/information/metal-additive-manufacturing$\underline{\text { materials }}$

[11] AMERICA MAKES \& ANSI ADDITIVE MANUFACTURING STANDARDIZATION COLLABORATIVE, “Standardization Roadmap for Additive Manufacturing," Version 2.0, (June 2018).

[12] ASTM INTERNATIONAL, "Standard Terminology for Additive Manufacturing - General Principles - Terminology,” ISO/ASTM 52900:2015 (E), (January 2016).

[13] L. SCIME, et.al, "Development of Monitoring Techniques for Binderjet Additive Manufacturing of Silicon Carbide Structures," Oak Ridge National Laboratory, ORNL/TM-2020/1724, (September 2020).

[14] J. SIMPSON et al., "Considerations for Application of Additive Manufacturing to Nuclear Reactor Core Components, ” Oak Ridge National Laboratory, ORNL/TM-2019/1190, (May 2019).

[15] L. SCIME et.al, "Development of Monitoring Techniques for Laser Powder Bed Additive Manufacturing of Metal Structures," Oak Ridge National Laboratory, ORNL/TM-2020/1708, (September 2020). 
[16] J. HALEY et al., "Review of Advanced Manufacturing Techniques and Qualification Process for Light Water Reactor - Laser Directed Energy Deposition Additive Manufacturing," Oak Ridge National Laboratory, (Draft in progress).

[17] A. L. COATES et al., "Critical Review of Industry Additive Manufacturing Qualifications," Oak Ridge National Laboratory, (Draft in progress).

[18] NATIONAL AERONAUTICE AND SPACE ADMINISTRATION, “Additive Manufacturing Requirements for Spaceflight Systems,” NASA-STD-6030, (April 2021).

[19] NATIONAL AERONAUTICE AND SPACE ADMINISTRATION, “Additive Manufacturing Requirements for Equipment and Facility Control,” NASA-STD-6033, (April 2021).

[20] FEDERAL AVIATION ADMINISTRATION, Memorandum, Subject: "Engineering Considerations for Powder Bed Fusion Additively Manufactured Parts, ” Dated: July $7^{\text {th }}, 2016$, AIR100-16-130-GM18, (July 2016).

[21] FEDERAL AVIATION ADMINISTRATION, Memorandum, Subject: “ASI Job Aid for Additive Manufactured Parts,” Dated: September 30"th , 2016, AIR100-16-110-GM26, (September 2016).

[22] AEROSPACE INDUSTRIES ASSOCIATION, "Recommended Guidance for Certification of AM Component," (February 2020).

[23] GRAND VIEW RESEARCH, "Healthcare Additive Manufacturing Market Size, Share \& Trends Analysis Report By Technology (Laser Sintering, Deposition Modeling), By Application (Medical Implants, Wearable Devices), By Material, And Segment Forecasts, 2021 - 2028, ” GVR-368038-693-6, (January 2021).

[24] FOOD AND DRUG ADMINISTRATION, "Technical Considerations for Additive Manufactured Medical Devices, Guidance for Industry and Food and Drug Administration Staff," (December 2017).

[25] U. S. DEPARTMENT OF DEFENSE, "Department of Defense Additive Manufacturing Strategy, " Office of the Under Secretary of Defense for Research and Engineering, (January 2021).

[26] U. S. DEPARTMENT OF DEFENSE, “Audit of the DoD's Use of Additive Manufacturing for Sustainment Parts," Office of Inspector General, DODIG-2020-003, (October 2019).

[27] GE ADDITIVE, “Accelerating Additive: GE 3D-Printed Metal Part Receives Air for Airworthiness Qualification," Press Release, Dated: June $9^{\text {th }}, 2021$, (June 2021).

https://blog.geaviation.com/manufacturing/accelerating-additive-ges-first-3d-printed-metal-partge-receives-air-force-airworthiness-qualification/

[28] U. S. DEPARTMENT OF DEFENSE, "Use of Additive Manufacturing in the DoD," DoD Instructions 5000.93, Change 1, (July 2021).

[29] AMERICAN SOCEITY OF MECHANICAL ENGINEERS, “Criteria for Pressure Retaining Metallic Components using Additive Manufacturing,” PB-13-2021, ISBN: 9780791874547, (2021).

[30] U. S. NUCLEAR REGULATORY COMMISSION, "NRC Regulatory Approach for Advanced Manufacturing Technologies, " Presentation by Carolyn Fairbanks at the Virtual Workshop on Advanced Manufacturing Technologies for Nuclear Applications, December $7^{\text {th }}-10^{\text {th }}, 2021$, ADAMS Accession Number: ML20344A422, (December 2021).

[31] ELECTRIC POWER RESEARCH INSTITUTE, "Qualification of Laser Powder Bad Fusion-AM for Nuclear Pressure Retaining Applications," Presentation by David W. Gandy at the DOE-NE 
AMM Annual Program Review, December $4^{\text {th }}-6^{\text {th }}, 2018$, (December 2018).

https://www.energy.gov/sites/prod/files/2019/02/f59/ne-amm-gandy-icme-in-situ-monitoring.pdf

[32] WESTINGHOUSE, "Westinghouse Installs First-of-a-Kind 3D -printed Fuel Component Inside Commercial Nuclear Reactor," Press Release dated: May 4 ${ }^{\text {th }}, 2020$, (May 2020).

https://info.westinghousenuclear.com/news/westinghouse-installs-first-of-a-kind-3d-printed-fuelcomponent-inside-commercial-nuclear-reactor

[33] U.S. DEPARTMENT OF ENERGY, “TVA Installs 3D-printed Fuel Assembly Brackets in a Commercial Reactor," Press Release dated: August 31 ${ }^{\text {st }}$, 2021, (August 2021).

https://www.energy.gov/ne/articles/tva-installs-3d-printed-fuel-assembly-brackets-commercialreactor

[34] M. RUSSELL et al., “TCR Data Management Plan,” Oak Ridge National Laboratory, ORNL/TM-2021/1942, (March 2021).

[35] M. RUSSELL and R. DEHOFF, “Quality Procedures for TCR Metal Core Structure Advanced Manufacturing Processes Report," Oak Ridge National Laboratory, ORNL/TM-2020/1736, (September 2020).

[36] M. RUSSELL et al., "Compilation of Quality Procedures for Ceramics Advanced Manufacturing Processes," Oak Ridge National Laboratory, ORNL/TM-2021/1974, (DATE).

[37] L. SCIME et al., "Report on Progress of Correlation of In-Situ and Ex-Situ Data and the Use of Artificial Intelligence to Predict Defects," Oak Ridge National Laboratory, ORNL/TM2020/1748, (September 2020).

[38] M. SNEAD et al., "Severe Accident Test Station," Oak Ridge National Laboratory, ORNL/TM2015/556, (September 2015). 
APPENDIX A. TERMINOLOGY 



\section{APPENDIX A. TERMINOLOGY}

- $\quad 10$ CFR 50.59 Process - A process used by NRC licensees to make changes to the licensed facility without NRC approval through a license amendment, provided the changes maintain acceptable levels of safety as documented in the facility safety analysis report [3]. Note - a similar process for DOE nuclear facilities is prescribed in 10 CFR 830.

- Additive Manufacturing (AM) / Advanced Manufacturing Technology (AMT) - umbrella terms to cover a broad range of novel and non-standardized manufacturing methods, such as 3-D printing, that have not been traditionally used in the United States nuclear industry and have yet to be formally standardized.

- Application Programming Interface (API) - Any set of common programmatic interfaces which allow Software Tools to communicate with each other or with the Digital Platform. Software Tools which interact directly with the Digital Platform utilize the Cardinal API.

- Augmented Intelligence (AI) - A term used to recognize that current Artificial Intelligence (described below) algorithms should always be used in tandem with a human domain expert for performance of safety critical tasks. The following are a general description of the progressive phases of AI:

- Descriptive AI analyzes raw data to identify process anomalies.

- Diagnostic AI summarizes large datasets for presentation or action.

- Predictive AI predicts relevant part properties based on process data.

- Prescriptive AI autonomously modifies a part design to improve its performance.

- Artificial Intelligence - An umbrella term referring to any computer algorithm which makes decisions which are intended to mimic those made by a human. Related concepts include the following:

- Machine Learning - Computer algorithms which learn to make decisions based on observation of training data.

- Deep Learning - Machine Learning algorithms which rely less strongly on human feature engineering to pre-process the data of interest.

- Heuristic - A human-engineered decision-making rule which can be implemented by a computer.

- Augmented Intelligence Relay (AIR)- A sequence of Artificial intelligence algorithms which ingest raw process data and predict relevant part properties. At each interface in the relay, human domain experts observe the intermediate results and perform feature-engineering in order to better structure the data. The relay approach is designed to reduce the number of expensive characterization tests which must be performed to achieve the goals of a predictive Augmented Intelligence.

- Binder jetting - An AM process performed in five steps:

(1) Each layer is configured with a specific set of process parameters.

(2) A rolling mechanism covers the build plate with a layer of powder.

(3) The print head moves in a pre-defined pattern over the build plate, depositing binder only when needed.

(4) A radiative heating element scans the build plate to dry the binder. 
(5) The stage supporting the build plate lowers to the desired layer thickness (typically 50 to $200 \mu \mathrm{m})$, and the process repeats until completion of the geometry.

- Certification - the act of determining, verifying, and attesting in writing to the qualifications of personnel, processes, procedures, or items in accordance with specified requirements.

- Chatter - condition in which the re-coater bounces vertically when spreading powder. Chatter typically occurs because of LPBF machine warpage or powder caught in the re-coater guide rails.

- Database - The collection of metadata comprising all of the digital threads for all of the components manufactured at the MDF. Strictly, the heavier process data (e.g. in situ images) are not stored in the database, they are stored within the designated file system(s) and the database only moderates and facilitates data upload and retrieval.

- Denudation - gas convection conditions under which powder feedstock is blown away from the melt pool.

- Digital Platform - The cyber-physical infrastructure under development at the MDF which is enabling novel design and qualification paradigms for advanced manufacturing.

- Digital thread - The totality of the design intent information and data collected during the fabrication of a component. The digital thread enables the instantiation of a corresponding digital twin model. Digital threads are ingested by the AIR in order to predict relevant part properties based on collected process data.

- Digital Tool - A web-based interface which allows users to interact with the database.

- Digital twin - A computer representation and model of a real object, assembly, or system. This model is updated based on data collected from its physical twin; this is in contrast to a computer model which relies solely on aggregated or representative data.

- Digital Workflow - The interaction between the physical manufacturing process, the human technicians, and the Digital Platform.

- Directed Energy Deposition - An AM process in which material is added to a small melt pool that is formed with focused thermal energy to build parts volume by volume.

- Laser Powder Bed Fusion - An AM process performed in five steps:

(1) Each layer is prepared with a specific printing scan strategy and associated process parameters such as laser power and speed.

(2) A raking mechanism covers the build plate with a layer of powder.

(3) The melting process programmed during step 1 is applied to the layer.

(4) The stage supporting the build plate lowers to the desired layer thickness (typically 20 to $80 \mu \mathrm{m})$.

- Operation - To facilitate scalability of the Digital Workflow, each manufacturing process is decomposed into a sequence of operations. A digital thread is then merely a list of all of the operations which were performed to fabricate the component.

- Qualification - characteristics or abilities that are measured again established requirements, such as standards or tests, that qualify a structure, system, or component.

- Safety class structures, systems, and components - the structures, systems, or components, including portions of process systems, whose preventive or mitigative function is necessary to 
limit radioactive hazardous material exposure to the public, as determined from safety analyses.

- Safety significant structures, systems, and components - the structures, systems, and components which are not designated as safety class structures, systems, and components, but whose preventive or mitigative function is a major contributor to defense in depth and/or worker safety as determined from safety analyses.

- Short feeding - a condition in which the re-coater spreads an incomplete layer of powder across the top surface of the build chamber, typically due to low powder dosing rates.

- Software Tool - Any custom or commercial software designed to facilitate a Digital Workflow or specific operation. The custom Software Tools are enumerated below.

○ Carrier Pigeon - Portable multi-modal image segmentation.

- Emerald - Microscopy data analytics tool suite.

○ Emu - Porosity and crack detection for Arcam NIR images.

- Falcon - Analysis of Arcam log file data.

- Peregrine - Data collection, analysis, and visualization for powder bed printers.

○ Pigeon - Advanced multi-modal image segmentation.

○ Raven - Part tracking for the CVI operation.

- SCOPS - DIC and thermal imaging for DED printers.

- Simurgh - AI enabled X-Ray CT reconstruction.

- SWAN - An API for powder bed printer log file analysis and spatial mapping.

- Spatter - large molten ejecta that leave the melt pool and is likely familiar to readers with a background in welding.

- Streaking - uneven powder spreading caused by worn re-coater blades.

- Swelling - volumetric expansion of a component, typically upward, which can prevent uniform powder spreading and may abrade the re-coater if severe. Swelling is caused by warping of components and is typically most severe at the perimeter of the components.

- Verification - the act of reviewing, inspecting, testing, checking, auditing, or otherwise determining and documenting whether items, processes, services, or documents conform to specified requirements (from NQA-1, 2008). 


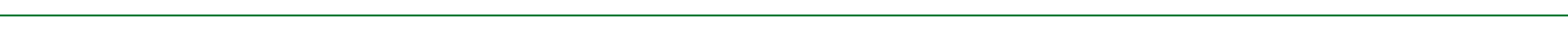

